
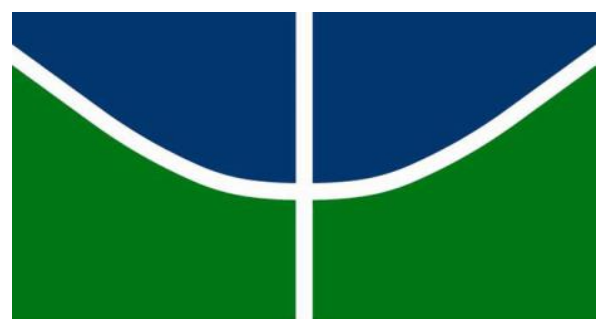

Universidade de Brasília

Instituto de Psicologia

Departamento de Processos Psicológicos Básicos

Programa de Pós-Graduação em Ciências do Comportamento

\title{
PADRÕES DE RASTREAMENTO NA VISUALIZAÇÃO DE FACES PRÓPRIAS E NÃO PRÓPRIAS
}

Ivan Bouchardet da Fonseca Grebot

Brasília, abril de 2016. 
Universidade de Brasília

Instituto de Psicologia

Departamento de Processos Psicológicos Básicos

Programa de Pós-Graduação em Ciências do Comportamento
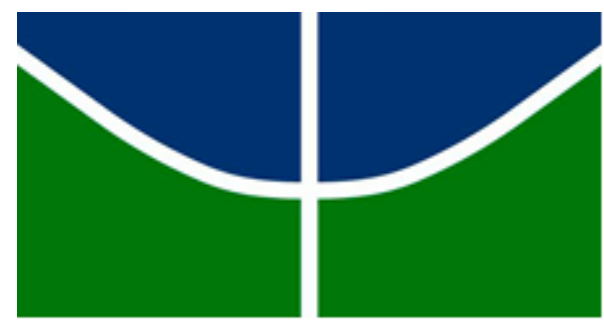

\section{PADRÕES DE RASTREAMENTO NA VISUALIZAÇÃO DE FACES PRÓPRIAS E NÃO PRÓPRIAS}

Ivan Bouchardet da Fonseca Grebot

Orientadora: Prof ${ }^{a}$. Dr ${ }^{\mathrm{a}}$. Wânia Cristina de Souza

Dissertação apresentada ao Programa de PósGraduação em Ciências do Comportamento do Departamento de Processos Psicológicos Básicos do Instituto de Psicologia da Universidade de Brasília, como requisito parcial à obtenção do título de Mestre em Ciências do Comportamento, na área de concentração: Cognição e Neurociências do Comportamento.

Brasília, abril de 2016. 


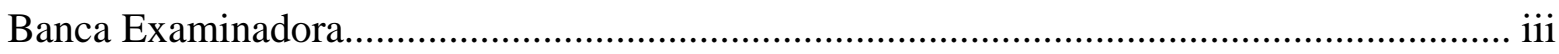

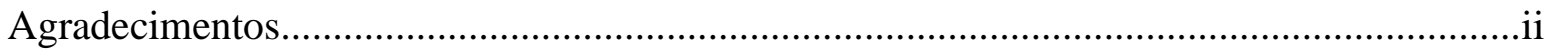

Lista de Siglas e Abreviaturas.........................................................................................

Lista de Figuras e Tabelas............................................................................................ vi

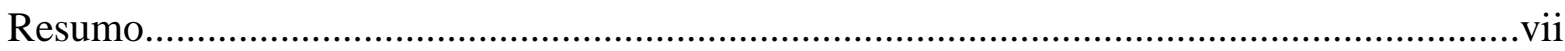

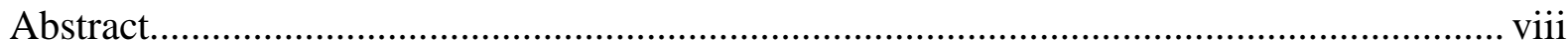

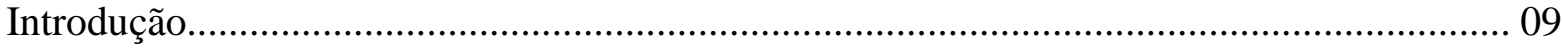

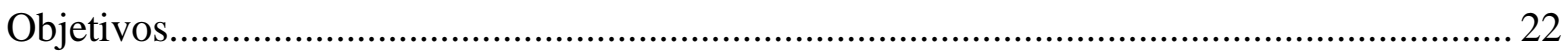

Hipótese

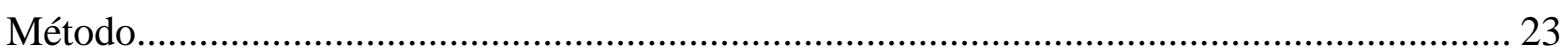

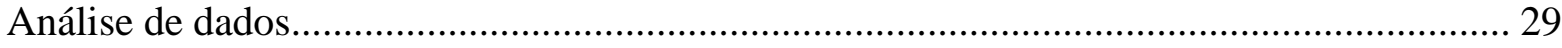

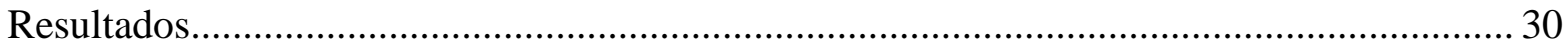

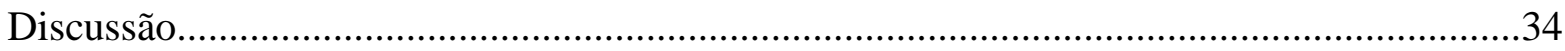

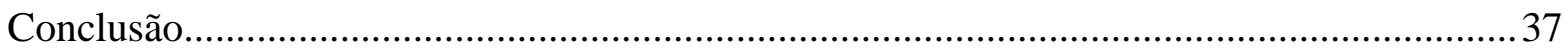

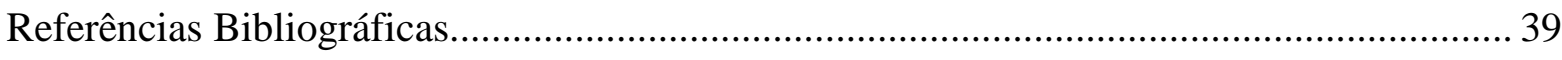

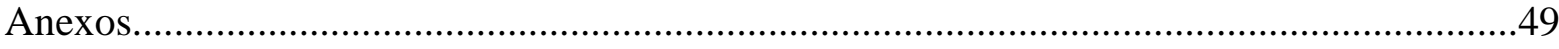

Anexo 1 - Termo de Consentimento Livre e Esclarecido.................................................. 49

Anexo 2 - Termo de Autorização de uso de imagem........................................................51

Anexo 3 - Questionário................................................................................................. 53

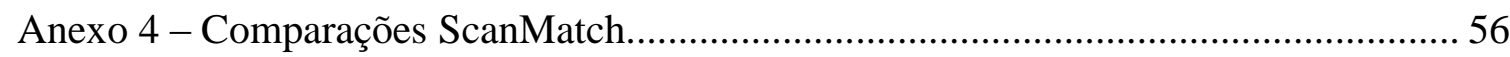


Universidade de Brasília

Instituto de Psicologia

Departamento de Processos Psicológicos Básicos

Programa de Pós-Graduação em Ciências do Comportamento

\section{BANCA EXAMINADORA}

Presidente: Prof ${ }^{a}$. Dr ${ }^{a}$. Wânia Cristina de Souza

Departamento de Processos Psicológicos Básicos

Instituto de Psicologia

Universidade de Brasília

Membro externo: Prof ${ }^{a}$. Dr ${ }^{a}$. Graziela Furtado Scarpelli Ferreira

Curso de Psicologia

Instituto de Educação Superior de Brasília - IESB

Membro interno: Prof. Dr. Luciano Grüdtner Buratto

Departamento de Processos Psicológicos Básicos

Instituto de Psicologia

Universidade de Brasília

Membro suplente: $\operatorname{Prof}^{\mathrm{a}}$. Dr ${ }^{\mathrm{a}}$. Goiara Mendonça de Castilho

Departamento de Processos Psicológicos Básicos

Instituto de Psicologia

Universidade de Brasília 


\section{Agradecimentos}

Primeiramente, agradeço aos meus pais e minha avó, pelo apoio e dedicação incondicional. O carinho e apoio de vocês, em todos os aspectos, me fazem acreditar na minha capacidade e me deixam seguro para encarar os desafios.

À minha orientadora, Prof ${ }^{\mathrm{a}}$. Dr ${ }^{\mathrm{a}}$. Wânia Cristina de Souza, pela orientação, dedicação e paciência, muitas vezes testada, mas que nunca desistiu.

Ao Prof. Dr. Luciano Grüdtner Buratto, pela troca de ideias, interesse e disposição em me auxiliar em dúvidas e problemas.

Aos meus amigos e colegas, dentro e fora da UnB, pelo apoio e pelos momentos de descontração, sem os quais eu não conseguiria ter mantido minha sanidade.

À Coordenação de Aperfeiçoamento de Pessoal de Nível Superior - CAPES, pelo apoio financeiro fornecido durante o período de realização do mestrado.

A todos que, direta ou indiretamente, me auxiliaram na realização desta pesquisa. 


\section{Lista de Figuras e Tabelas}

Figura 1. Modelo teórico de reconhecimento de faces de Bruce e Young 11

Figura 2. Modelo neurológico de reconhecimento de faces de Haxby, Hoffman e Gobbini..... 13

Figura 3. Músculos oculomotores. 18

Figura 4. ViewPoint EyeTracker 220Hz Binocular USB with HeadLock. 25

Figura 5. Apresentação de estímulos: Foi apresentada uma tela branca, seguida de uma cruz de fixação fora da área da face por 2 segundos e o estímulo de face, por $1500 \mathrm{~ms}$ 28

Figura 6. Conversão de uma sequência de fixações em uma sequência de caracteres pela aplicação de uma máscara, no método de Levenshtein. 29

Figura 7. Índices de semelhança entre sequências familiar e não-familiar (FAM / NFAM), familiar e própria (FAM / PR) e não-familiar e própria (NFAM / PR), por fixação. 31

Figura 8. Localização média por fixação, para cada categoria de estímulo. 32

Figura 9. Porcentagem de tempo passado em cada ROI. 33

Tabela 1. Descrição dos grupos de estímulos e sua distribuição. .28 


\section{Lista de Siglas e Abreviaturas}

BAI: Beck Anxiety Inventory

BC: Boca

BDI: Beck Depression Inventory

CAEE: Certificado de Apresentação para Apreciação Ética

cm: Centímetro(s)

dp: Desvio padrão

FAM: Familiar

FRU: Face recognition unit

h: Hora(s)

ms: Milissegundos

$\mathbf{m}^{2}$ : Metro-quadrado

NFAM: Não familiar

NimStim: NimStim Set of Facial Expressions

NZ: Nariz

OD: Olho direito

OE: Olho esquerdo

PIN: Person identity node

PR: Própria

ROI(s): Região(ões) de interesse

S: Segundo(s) 


\section{Resumo}

A face é o principal meio de comunicação do qual dispomos, permitindo-nos extrair informações essenciais para o convívio social. A forma como se dá o reconhecimento de faces, portanto, tem sido objeto de grande interesse de pesquisadores de diversas áreas. Um dos elementos do reconhecimento de faces é o grau de familiaridade da face que observamos. Embora haja fortes evidências do processamento holístico de faces, estudos têm apontado diferenças no processamento de faces familiares e não familiares. A presente pesquisa buscou avaliar se existe um padrão de rastreamento visual para faces de diferentes graus de familiaridade. Para tal, utilizou-se a estratégia de eye-tracking para comparar faces familiares, não familiares e próprias durante uma tarefa de visualização livre em estudantes universitários. Os resultados foram analisados por meio da medida da distância de Levenshtein entre categorias, utilizando o algoritmo de Needleman-Wunsch. Observou-se uma grande semelhança entre os padrões de rastreamento das três categorias quando analisadas as trajetórias da primeira à quarta fixação. No entanto, na comparação das sequências, as faces próprias se mostraram pouco semelhantes às demais categorias.

Palavras chave: Rastreamento ocular, Reconhecimento de face, Familiaridade, Face própria. 


\begin{abstract}
The face is our main path for communication. It allows us to extract vital information to social interaction. How face recognition happens has been an object of great interest to researchers of several fields. One aspect of face recognition is how familiar a face is to us. Although there is strong evidence for holistic processing of faces, studies have shown diferences in the processing of familiar and unfamiliar faces. This research aimed to investigate the existence of a pattern in the visual scanpath of faces in different degrees of familiarity. In order to achieve this, the eye-tracking methodology was used to compare familiar, unfamiliar and self faces of university students during a free viewing task. Results were analyzed by measuring the Levenshtein distance between categories, using the Needleman-Wunsch algorithm. When analyzing the first four fixations, a great similarity was observed between the three categories. However, when comparing the sequences, self-faces were shown to have little similarity to the other two categories.
\end{abstract}

Key words: Eye-Tracking, Face recognition, Familiarity, Self-face. 
A face é a mais importante ferramenta de comunicação que temos. Em animais, bem como em humanos, nuances de expressão facial podem sinalizar ameaça ou submissão. A face é, portanto, crucial para a organização social da espécie humana, permitindo-nos identificar e sermos identificados por indivíduos do mesmo grupo ou de outros grupos, haja vista as claras vantagens adaptativas na capacidade de identificar indivíduos diferentes da mesma espécie, bem como identificar se esses indivíduos são amigáveis ou hostis (Barrett, 2008). A face permite ainda, a identificação e comunicação de outros sinais importantes para a manutenção social, tais como estados emocionais, atração sexual e identidade individual (Darwin, 1872/2009; De Souza, Feitosa, Eifuku, Tamura \& Ono, 2008). Consequentemente, a percepção de faces tem sido amplamente estudada por diversas áreas do conhecimento.

No que diz respeito à organização social de primatas, a habilidade de reconhecer faces permite o desenvolvimento de grupos sociais com relações entre os indivíduos que compõem o grupo. Primatas apresentam preferência inata por configurações espaciais que se assemelham a faces (Parr, 2014). Bebês humanos mostram preferência por faces a outros objetos (Morton \& Johnson, 1991), o que reforça a especializações cognitiva e neural associadas ao processamento de faces.

Há uma área cerebral especializada no reconhecimento de faces, localizada entre os lobos temporal e occipital, primariamente no hemisfério direito, o giro fusiforme, que responde seletivamente à estímulos de face (Kanwisher \& Yovel, 2006; McCarthy, Luby, Gore \& Goldman-Rakic, 1997). Embora haja consenso quanto à existência de uma rede neural especializada no reconhecimento e processamento de faces, os mecanismos pelos quais isso se dá ainda não são totalmente conhecidos.

O principal modelo teórico de reconhecimento de faces foi proposto por Bruce e Young (1986), no artigo clássico Understanding face recognition. O modelo define o reconhecimento de faces como ocorrendo em estágios e define dois grandes sistemas: um sistema de codificação estrutural e um sistema cognitivo. O modelo também define a produção de descrições em 
diversos estágios, que obtidas a partir da codificação de informações visuais, durante o processo de reconhecimento de face.

Quando uma face é vista, inicia-se o reconhecimento de face, por meio do sistema de codificação estrutural. Nesse estágio, é produzido um conjunto de descrições que incluem descrições centradas na visão (view-centered descriptions), que contêm informações acerca da movimentação da boca e da configuração dos elementos da face para análise da expressão facial e descrições independentes de expressão (expression-independent descriptions). As descrições independentes de expressão encaminham informação às unidades de reconhecimento facial (face recognition units - FRUs), que contêm códigos estruturais que descrevem cada uma das faces conhecidas. A ativação das FRUs envia sinais ao sistema cognitivo e é proporcional à semelhança da descrição armazenada com a informação recebida por meio do input visual. A ativação das FRUs pode ter influência dos nódulos de identidade pessoal (person identity nodes - PINs), que contêm informações semânticas relacionadas à identidade específica. Há portanto, um PIN para cada pessoa conhecida. A ativação dos PINs pode se dar pelo reconhecimento da voz ou nome, além da visualização da face e dão acesso à informação do nome da pessoa.

As informações processadas nos componentes são finalmente encaminhadas para o sistema cognitivo, que retém a memória associativa relacionada com as informações. O sistema cognitivo é responsável pela distribuição da atenção aos vários componentes e pelo processamento e análise das informações recebidas (Bruce \& Young, 1986). 


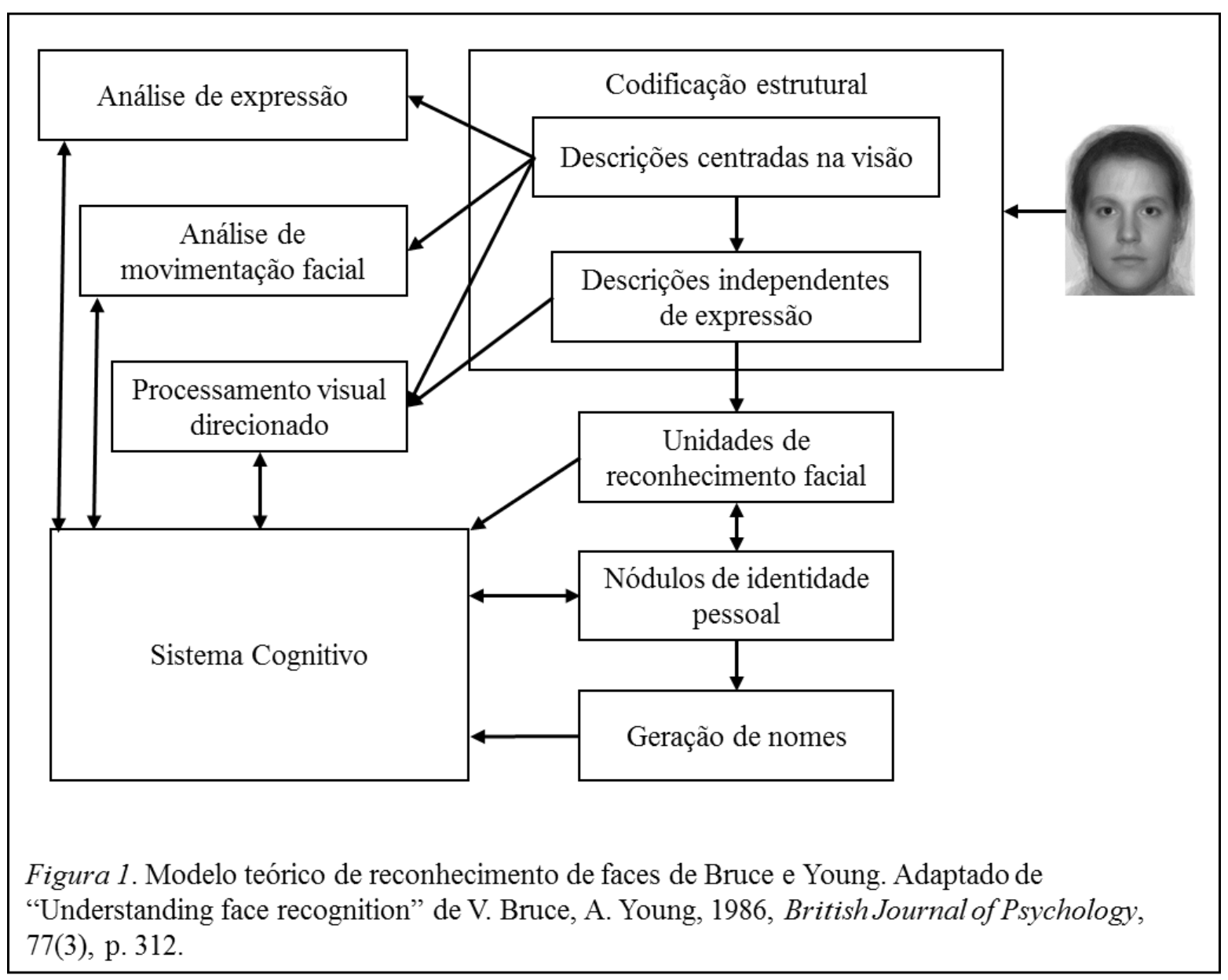

O modelo de Bruce e Young (1986) propõe um processamento divergente para faces familiares e não familiares, sendo essa distinção feita pelo processamento visual dirigido. Apenas o processamento de faces familiares acessa as unidades de reconhecimento facial, os nódulos de identidade pessoal e as informações de nome. Assim, a análise estrutural de uma face familiar fornece informações mais ricas e detalhadas do que a de uma face não familiar, pois, enquanto a análise visual de uma face não familiar estabelece informações estruturais e um código pictórico (informações descritivas de um padrão ou imagem), faces familiares permitem a formação de códigos semânticos, em adição às informações obtidas de faces não familiares (Bruce, 1982; 1986).

A discussão sobre como se dá a organização da percepção de faces em nível neural, tem girado em torno de dois modelos. O primeiro modelo propõe a existência de um "módulo" 
especializado em reconhecimento de faces, comumente associado ao giro fusiforme (Kanwisher, McDermott \& Chun, 1997). O segundo modelo propõe que o reconhecimento de faces se dá através de uma rede neural distribuída (Haxby et al., 2001; Ishai, 2008; Ishai, Schmidt \& Boesiger, 2005).

Assumindo vários paralelos ao modelo proposto por Bruce e Young (1986), Haxby, Hoffman e Gobbini (Haxby, Hoffman \& Gobbini, 2000) propõem um modelo neurológico para o processamento de faces, composto por um sistema central (core system), onde ocorreria a análise visual do estímulo e um sistema estendido (extended system), onde seria processado o significado da informação gerada pela análise visual.

Ao se iniciar a análise visual de uma face, no sistema central, as informações básicas sobre a configuração e elementos componentes da face são processadas no giro occipital inferior, que encaminha a informação ao giro fusiforme lateral e ao sulco temporal superior. As informações processadas nessas duas áreas se dividem em aspectos mutáveis e imutáveis da face. Os aspectos imutáveis da face, associados à identidade, são processados no giro fusiforme lateral. Já os aspectos mutáveis da face, processados no sulco temporal superior, são aspectos importantes para a comunicação social, como a expressão facial, direção do olhar e movimentação dos lábios.

O sistema estendido é composto por quatro áreas que interagem como o córtex visual estriado: o sulco intraparietal, envolvido na percepção e atenção espacial; o córtex auditivo, envolvido na percepção do discurso pré-lexical, como a movimentação dos lábios; o sistema límbico, amígdala e ínsula, envolvidos na percepção de emoções e expressões emocionais e a região temporal anterior, envolvida no processamento de informações biográficas e de identidade pessoal (Haxby, Hoffman \& Gobbini, 2000). 


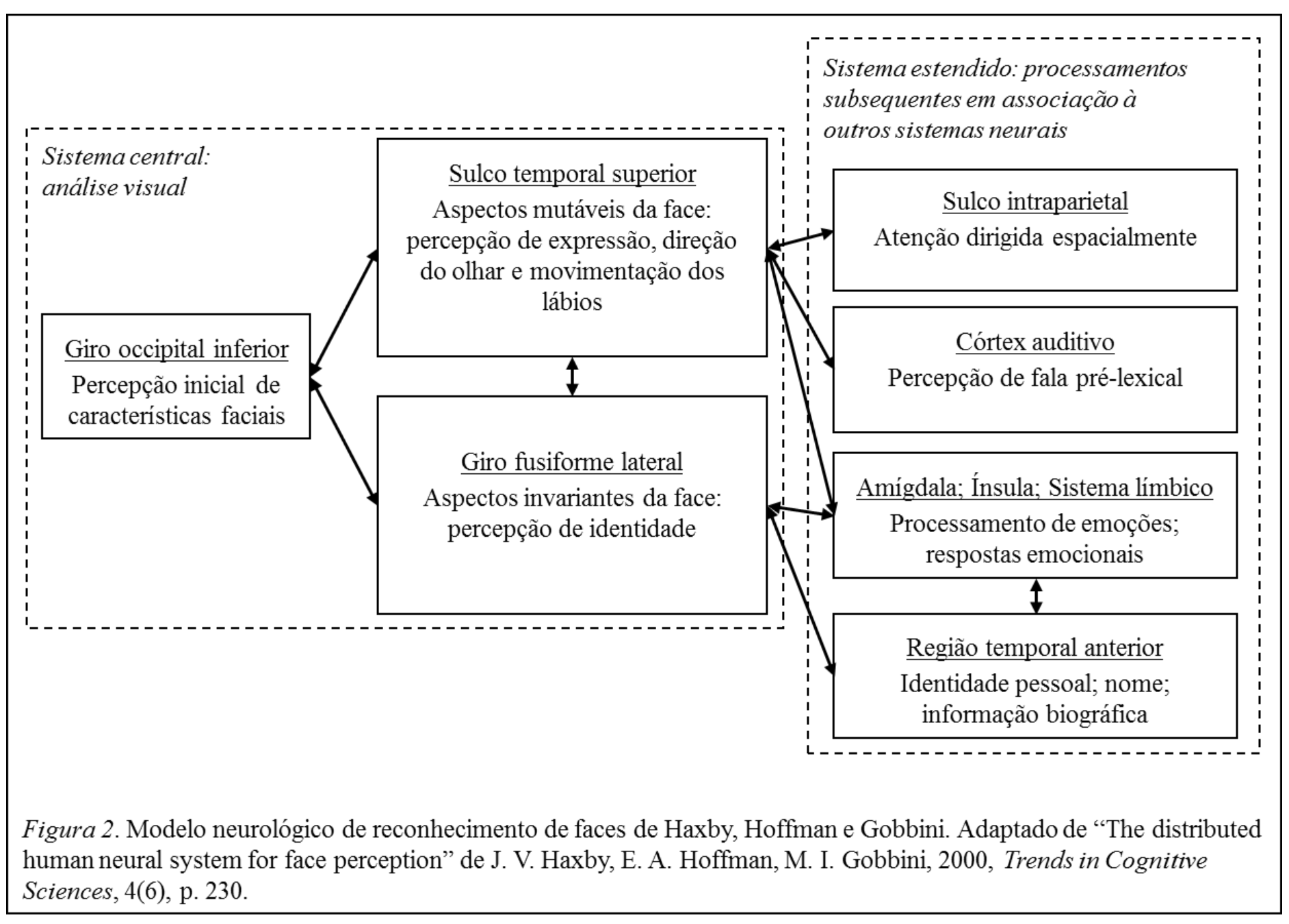

Estudos realizados com pacientes com prosopagnosia, uma deficiência seletiva na habilidade de reconhecer faces, mas não objetos, mostraram uma dissociação entre circuitos neurais distintos para o processamento de faces e objetos. Haxby, Hoffman \& Gobbini (2000) propõem um modelo neural para o processamento de faces com uma estrutura hierárquica. Haveria, então, um sistema central para a análise de faces e um sistema para o processamento do significado das informações extraídas das faces. O circuito neural de processamento de faces é composto por estruturas que respondem seletivamente à estímulos de face. O sistema central envolveria regiões bilaterais do córtex extra-estriado occipito-temporal (Haxby, Hoffman \& Gobbini, 2002).

O reconhecimento de faces envolve duas estratégias de processamento complementares, o processamento holístico e o processamento categórico. Diamond e Carey (1986) propõem que 
o processamento de um estímulo visual é sensível às configurações de primeira e segunda ordem. As configurações de primeira ordem permitiriam a diferenciação entre faces e objetos e as configurações de segunda ordem se referem à disposição espacial de elementos faciais em relação à outros elementos faciais, o que permitiria a diferenciação entre faces individuais. As informações referentes à configuração de elementos faciais, como descritos na configuração de primeira ordem, seriam processadas de forma integrada, por um processamento holístico. Já as informações referentes às configurações de segunda ordem, seriam processadas pelos elementos da face, no processamento por características (McKone \& Robbins, 2010; Burke \& Sulikowski, 2013). O processamento holístico de faces poderia, portanto, ser definido como o reconhecimento do estímulo de face, onde os elementos do estímulo e as relações espaciais dos mesmos são representados como um todo.

\section{Familiaridade: faces próprias, familiares e não familiares}

Um dos elementos fundamentais do reconhecimento de faces é o grau de familiaridade. Faces familiares são definidas por Johnston e Edmonds (2009) como faces famosas, faces pessoalmente familiares ou faces não familiares estudadas durante uma fase de treino de forma a tornarem-se familiares. Faces em diferentes graus de familiaridade eliciam respostas neurais distintas e, embora ainda não esteja claro quais estruturas são específicas ao processamento de faces em diferentes graus de familiaridade, diversas estruturas cerebrais bilaterais estão associadas ao processamento de faces, tais como o giro fusiforme, sulco temportal superior e giro occipital inferior (Eifuku et al., 2011; Gobbini \& Haxby, 2006; Gobbini \& Haxby, 2007). Bebês humanos já são capazes de diferenciar um rosto familiar de um não familiar, com 45 horas de vida e a própria face, antes dos dois anos de idade (Field, Cohen, Garcia \& Greenberg, 1984; Amsterdam, 1972).

Os conceitos de familiaridade e identificação são fatores importantes na cognição social, que propõe uma correlação direta entre o processo de aprendizagem e aquisição de 
conhecimento à observação de modelos. Dessa forma, uma maior familiaridade com o modelo implicaria uma maior identificação entre o observador e o modelo, por consequência levando a um processo de aprendizagem mais eficiente (Bandura, 1988; Bandura, 1989).

Gobbini e Haxby (2007) encontraram diferenças na ativação cerebral de áreas relacionadas ao processamento de faces ao variar os estímulos apresentados em termos de grau de familiaridade. No entanto, não houve relação direta entre ativação e grau de familiaridade no giro fusiforme, mas sim no córtex paracingulado anterior, pré-cúneo e sulco temporal superior. Para padrões de rastreamento, entre faces familiares e não familiares, estudos apontam para um padrão de rastreamento similar até a segunda fixação, o que poderia ser justificado por um processamento comum de aquisição de informação acerca da face, que se diferenciaria posteriormente para faces familiares e não familiares (Van Belle, Ramon, Lefèvre \& Rossion, 2010; Kita et al., 2010).

Tarefas de reconhecimento de faces familiares e não familiares sugerem que há diferenças na representação cognitiva de faces com diferentes graus de familiaridade. Para faces familiares, haveria uma representação holística. No entanto, para faces não familiares ocorre um reconhecimento por composição de atributos, similar ao que ocorre com objetos (Biederman \& Kalocsai, 1997; Eifuku et al., 2003).

Faces próprias possuem alguns atributos particulares. Inicialmente, as formas de se acessar a própria face são diferentes das formas de acesso à outras faces. Além de imagens e vídeos, apenas espelhos permitem a visualização da própria face e, nesses últimos, ocorre um efeito de inversão visual. Durante a visualização da própria face, espelhos e fotografias eliciam respostas neurais diferentes, com fotografias eliciando respostas de maior amplitude dos componentes de potencial evocado P100 e N170 (Butler, Mattingley, Cunnington \& Suddendorf, 2012). Além do acesso diferenciado, a própria face elicia informações autorreferenciais, o que por sua vez, são processadas distintamente de informações e estímulos não autorreferenciais. Estudos tem apontado para a predominância do hemisfério direito no 
processamento de informação autorreferencial, incluindo portanto, a própria face (Platek, Wathne, Tierney \& Thomson, 2008; Devue et al., 2007; Devue \& Brédart, 2011; Keenan et al., 2000).

Greenberg e Goshen-Gottstein (2009) sugerem que o processamento da própria face é baseado nos atributos individuais da face. Além disso, estudos mostram que estímulos de própria face são identificados mais rapidamente que outros estímulos (Tong \& Nakayama, 1999) e recebem maior atenção, em relação a faces familiares e não familiares (Devue, Van der Stigchel, Bredart \& Theeuwes, 2009). A própria face é extremamente difícil de ser ignorada pelo próprio indivíduo. Algumas possíveis explicações para as particularidades da própria face são o grau de familiaridade do indivíduo com a própria face e a relevância emocional da própria face, evidenciada pela ativação neural de estruturas do sistema límbico durante a visualização da própria face (Bredart, Delchambre \& Laureys, 2006).

Embora muitos estudos apontem para a participação de processamento ascendente (bottom-up) no reconhecimento de faces, há também um forte componente descendente (topdown) no reconhecimento de faces, dirigido por conceitos, expectativas, representações mentais e memória (Li et al., 2009). No caso de própria face, achados experimentais sugerem que representações mentais robustas são um dos motivos pelos quais a própria face tem vantagens sobre outros estímulos. No entanto, o conceito de representações mentais robustas difere do conceito de familiaridade no sentido de permitir, por exemplo, o rápido reconhecimento a despeito da orientação do estímulo (Tong \& Nakayama, 1999).

\section{Anatomia do olho humano}

Os olhos são os órgãos sensoriais especializados na localização detecção e análise dos componentes luminosos do ambiente. O olho humano é composto por pupila, esclera ou esclerótica, íris, córnea, cristalino, corpo ciliar, coroide, humor vítreo e nervo óptico (Schiffman, 2005). 
A pupila é a abertura que permite a entrada a luz até a retina. Em torno da pupila está a íris, que contém a pigmentação que dá cor ao olho. A íris está ligada a dois músculos capazes de contrair ou dilatar, afetando o tamanho da pupila. A córnea cobre a íris e a pupila e, juntamente com a esclera, formam o globo ocular (Schiffman, 2005).

Os estímulos luminosos entram no olho através da pupila, sendo antes refratados na córnea e seguem até a retina. O cristalino, posicionado atrás da íris, atua como uma lente, alterando seu formato para permitir o foco correto dos estímulos luminosos.

$\mathrm{Na}$ retina, as informações visuais são captadas pelos fotorreceptores. As informações são encaminhadas então pelo nervo óptico que reúne os axônios da retina e sai do olho pela parte posterior do mesmo, em direção ao cérebro, especificamente para o lobo occipital, onde é processado o input visual (Bear, Connors \& Paradiso, 2010).

No centro de cada retina, há uma região amarelada, chamada de mácula lútea, responsável pela visão central (em oposição ao que se chama visão periférica). Nessa região encontra-se a fóvea, uma área caracterizada por uma depressão na retina, com cerca de dois milímetros de diâmetro, de onde partem as informações visuais para o restante do processamento encefálico.

A passagem do estímulo visual inicia-se na camada de fotorreceptores, seguindo para uma camada de células bipolares e, finalmente, chegando à camada de células ganglionares, a partir de onde segue para os neurônios do lobo occipital.

O olho é sustentado por seis músculos, que auxiliam na movimentação dos olhos, aumentando o alcance e a velocidade de visualização. São eles: oblíquo superior, oblíquo inferior, reto superior, reto medial, reto lateral e reto inferior. Os músculos oculomotores permitem a movimentação livre dos olhos, inclusive de torção do globo ocular em volta do eixo visual, perpendicular à retina, embora o movimento de torção seja extremamente sutil e de baixa amplitude (Schiffman, 2005). Esses seis músculos se organizam em três pares, que permitem a movimentação do olho em qualquer direção em um plano bidimensional. Em adição 
à movimentação tridimensional dos olhos, os olhos podem se mover em torno dos eixos visuais, em uma movimento chamado torção ocular. Os músculos oculomotores estão ilustrados na Figura 3.

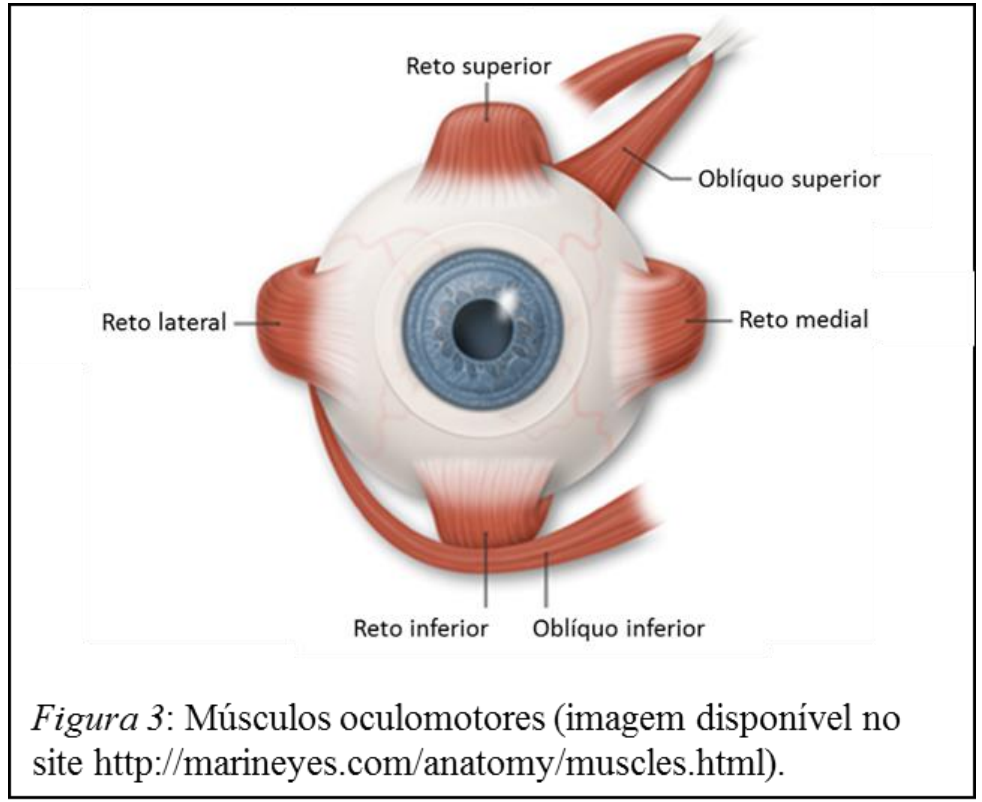

\section{Eye-Tracking}

A estratégia de Eye-Tracking permite a identificação e o registro de movimentos oculares em um ambiente real ou controlado, em alta precisão e de forma não invasiva (Barreto, 2012), o que traz boa validade ecológica para este método de registro. Devido à gradual redução do custo financeiro e ao surgimento de aparelhos disponíveis comercialmente, a técnica de rastreamento ocular tem se tornado extremamente popular em pesquisas de diversas áreas.

A metodologia de rastreamento ocular pode ser dividida em quatro grandes categorias: eletro-oculografia, bobina ocular, foto-oculografia e rastreadores de pupila baseados em câmeras, sendo a última categoria a mais utilizada atualmente em pesquisas com humanos. Embora o método de rastreamento mais utilizado em humanos com rastreadores com vídeo seja o rastreamento de pupila, também são utilizados métodos que combinam o rastreamento de pupila com a primeira imagem de Purkinje, também chamada de glint. As imagens de Purkinje são reflexos de estruturas do olho (Duchowski, 2006). As quatro imagens de Purkinje mais 
comuns referem-se àos reflexos da superfície externa da córnea (primeira imagem de Purkinje), superfície interna da córnea (segunda imagem de Purkinje), superfície externa da lente (terceira imagem de Purkinje) e superfície interna da lente (quarta imagem de Purkinje) (Duchowski, 2006). Esse método combina as posições da pupila e das imagens de Purkinje em um vetor, sendo assim menos susceptíveis a erros causados por pequenos movimentos da cabeça (Toh, Rossell \& Castle, 2011; Duchowski, 2006).

Em relação aos movimentos oculares propriamente ditos, pode-se destacar cinco tipos de movimentos oculares: fixações, sacadas, smooth pursuits (pequenos movimentos - tradução própria), reflexos oculares e microssacadas. Para os objetivos do presente trabalho, serão explorados apenas os dois primeiros.

Fixações referem-se a períodos entre movimentos de sacada, smooth pursuits e reflexos oculares, durante os quais os olhos aparentam estar imóveis. Devido aos avanços das técnicas de rastreamento ocular, foi evidenciado que durante as fixações os olhos não permanecem imóveis. Durante esse período, ocorrem movimentos com amplitudes inferiores a $1^{\circ} \mathrm{e}$, portanto, o termo "movimento fixional" passou a ser utilizado (Werner \& Chalupa, 2014).

Sacadas referem-se à movimentos rápidos e balísticos, que tem como função reposicionar a fóvea em relação ao estímulo visual. Sacadas são caracterizadas por rápidas acelerações iniciais e desacelerações finais. Dessa forma, informações visuais novas não são adquiridas durante as sacadas. Em humanos normais, espera-se até quatro sacadas por segundo, dependendo da tarefa realizada ou estímulo apresentado, com durações variando entre 20 e 40ms (Werner \& Chalupa, 2014).

Aparelhos de rastreamento visual permitem a coleta de diversas medidas, dependendo da resolução do aparelho e dos algoritmos usados para processar os dados coletados em sua forma "bruta". As medidas mais comuns são as medidas de posição: o posicionamento do olho em um plano bidimensional, que corresponde a um conjunto de coordenadas na tela de apresentação do estímulo. Outras medidas aferidas podem se referir a medidas de tamanho de 
pupila, tempo de permanência em uma determinada região do campo bidimensional ou a detecção de eventos visuais, como piscadelas ou movimentos oculares, extraídos dos dados brutos por parâmetros pré-determinados.

Tatler e Vincent (2008), ao registrar os movimentos oculares de participantes em tarefa de visualização livre, observaram que os eventos oculares não são independentes ou aleatórios. O registro dos movimentos oculares tem sido amplamente utilizado em pesquisas, como forma de investigação do funcionamento cognitivo subjacente ao comportamento visual (Malcolm \& Henderson, 2010) e as relações entre movimentos oculares e percepção visual (MartinezConde, Macknik \& Hubel, 2004).

\section{Rastreamento visual}

O conceito de rastreamento visual corresponde à descrição dos eventos oculares em um determinado período de tempo (Holmqvist et al., 2011).

Neisser (1967) e Yarbus (1967) destacam a participação de processos cognitivos no rastreamento visual, onde os olhos se direcionariam para atributos ou regiões que forneçam informações relevantes para o reconhecimento ou categorização do estímulo. DeAngelus e Peltz (2009) destacam o papel do processamento cognitivo no comportamento ocular, particularmente de processamento top-down. Yarbus (1967) afirma que os padrões de rastreamento visual e fixações oculares em relação a um determinado estímulo visual pode fornecer insights acerca dos processos cognitivos subjacentes ao estímulo, em relação ao observador.

Portanto, tendo em vista que as diferentes especializações no processamento de faces envolvem substratos neurais diferentes, embora não excludentes, mas que o padrão de rastreamento de faces familiares e não familiares apresenta diferenças, faz sentido investigar se o padrão de rastreamento visual de uma imagem da face de um indivíduo, pelo próprio 
indivíduo, é diferente do padrão de rastreamento visual de imagens de faces familiares e não familiares.

Dada a relevância de investigar os padrões de rastreamento visual de imagens de faces com diferentes graus de familiaridade, surge a necessidade de acessar os movimentos oculares. Como demonstrado por Yarbus (1967), ao se observar um mesmo estímulo visual, com a alteração da tarefa altera-se também o padrão de rastreamento visual. Há portanto, uma forte relação entre tarefa e estilo de rastreio e, por conseguinte, uma relação entre o rastreamento visual e os processos atencionais, bem como demais processos cognitivos adjacentes ao comportamento ocular (Yarbus, 1967; Nummenmaa, Hyönä \& Calvo, 2006), o que torna o rastreamento visual uma ferramenta importante no estudo de processos cognitivos e comportamentais, bem como uma fonte confiável de dados correlacionáveis ao estudo dos substratos neurais subjacentes aos mesmos.

O rastreamento visual pode ser alterado por transtornos como esquizofrenia (Levy, Sereno, Gooding \& O’Driscoll, 2010) e transtornos de humor, como mostram Armstrong e Olatunji (2012). No estudo realizado pelos mesmos, sujeitos ansiosos e sujeitos depressivos foram comparados com controles, durante tarefas de visualização livre e busca visual. No transtorno de ansiedade social, observa-se a alteração do rastreamento visual, com a evitação do rastreamento dos olhos, em estímulos de face (Schulze, Renneberg \& Lobmaier, 2013; Chen, Thomas, Clarke, Hickie \& Guastella, 2015). 


\section{Objetivos}

Teve-se como objetivo geral, a comparação dos padrões de rastreamento visual de estímulos de faces em diferentes graus de familiaridade: faces familiares, faces não familiares e a própria face, em alunos universitários. Além disso, buscaram-se os seguintes objetivos específicos:

\section{Objetivos específicos}

$\rightarrow$ avaliar se há uma tendência no padrão de rastreamento visual para faces familiares;

$\rightarrow$ avaliar se há uma tendência no padrão de rastreamento visual para faces não familiares;

$\rightarrow$ avaliar se há uma tendência no padrão de rastreamento visual para faces próprias;

$\rightarrow$ identificar como faces próprias, familiares e não familiares se diferenciam quanto ao rastreamento visual.

\section{Hipótese}

A presente pesquisa propõe a hipótese de que o padrão de rastreamento visual não depende do grau de familiaridade de uma face, em uma tarefa de visualização livre. Além disso, é esperado que para cada tipo de face haja uma tendência de trajetória visual, isto é, que a visualização de faces familiares produza padrões de rastreamento visual semelhantes, o que se repetiria para faces não familiares e faces próprias. 


\section{Método}

Esta pesquisa foi aprovada pelo Comitê de Ética do Instituto de Ciências Humanas da Universidade de Brasília (CAAE 43263015.7.0000.5540) e não foi oferecido nenhum tipo de remuneração para os participantes em nenhum momento da pesquisa.

\section{Participantes}

Participaram da pesquisa, 57 alunos universitários de ambos os sexos (66\% mulheres), com idades entre 18 e 37 anos $(\mathrm{dp}=3.6)$ e visão normal ou corrigida. Os participantes foram recrutados entre estudantes de graduação e pós-graduação da Universidade de Brasília.

Dos 57 participantes, 9 foram excluídos dos dados por problemas técnicos durante a coleta dos dados de rastreamento ocular, gerando dados não utilizáveis e, posteriormente, mais 4 foram excluídos por obterem pontuação considerada grave nas escalas de depressão (entre 36 e 63 pontos) ou de ansiedade (entre 31 e 63 pontos). Após as eliminações, 44 participantes foram considerados válidos.

\section{Materiais}

a) Instrumentos

1) Inventário Beck de Depressão (BDI): questionário composto por 21 grupos de afirmações. Cada grupo permite que o respondente escolha uma dentre quatro opções de respostas, às quais é atribuído um escore independente. Ao final do preenchimento de todo o inventário, é possível obter-se a estimativa de um possível quadro depressivo, conforme o escore total obtido. A pontuação obtida no instrumento indica a presença de um quadro clínico depressivo na seguinte relação: mínimo entre 0 - 11 pontos, leve entre 12 - 19 pontos; moderado entre $20-35$ pontos e grave entre $36-63$ pontos $\mathrm{A}$ 
estimativa de tempo para resposta ao instrumento é de 5 a 10 minutos, conforme o próprio manual (Cunha, 2001).

2) Escala Beck de Ansiedade (BAI): também utilizado em escala mundial, o Inventário Beck de Ansiedade é composto por 21 itens visando avaliar aspectos relacionados a manifestações de sintomas ansiosos. Diante da lista de sintomas apresentados, o participante avaliado deve escolher a frequência com que tais sintomas manifestam-se em seu dia-a-dia, podendo indicar respostas desde "absolutamente não" até "gravemente". Ao final, o instrumento gera um escore relacionado à intensidade com que os sintomas ansiosos mostram-se presentes para o respondente, sendo considerado mínimo o nível de ansiedade das pessoas que obtiveram entre 0 - 10 pontos, leve entre $11-19$ pontos; moderado entre $20-30$ pontos e grave entre $31-63$ pontos. $\mathrm{O}$ tempo para resposta ao instrumento gira, também, em torno de 5 a 10 minutos (Cunha, 2001).

3) Termo de Consentimento Livre e Esclarecido - TCLE (Anexo 1).

4) Termo de autorização de uso de imagem (Anexo 2).

5) Questionário elaborado para a investigação do histórico psiquiátrico, estado mental e informações relativas à visão do participante (Anexo 3).

\section{b) Equipamento}

As imagens de faces utilizadas como estímulos foram coletadas com uma câmera fotográfica da marca Nikon, modelo Coolpix P510, fixada em um tripé para estabilidade e tratadas com o software Adobe Photoshop CS6.

Para o registro do padrão de rastreamento visual, foi utilizado um equipamento de eye-tracking, modelo ViewPoint EyeTracker $220 \mathrm{~Hz}$ Binocular USB with HeadLock (Figura 4), da marca Arrington Research, com taxa de atualização de 220 hertz. O software utilizado durante a coleta foi o software ViewPoint. 


\section{c) Ambiente}

As coletas foram realizadas em uma sala do Laboratório de Psicobiologia da Universidade de Brasília. A sala mede aproximadamente $4 \mathrm{~m}^{2}$, contendo duas mesas de apoio, um computador acoplado ao Eye-Tracker, um monitor e uma televisão, onde são apresentados os estímulos, além de cadeiras para acomodação do participante e experimentador. O posicionamento do Eye-Tracker e, consequentemente, do participante, é centralizada em relação à tela da televisão, podendo ser ajustado conforme a necessidade individual de cada participante.

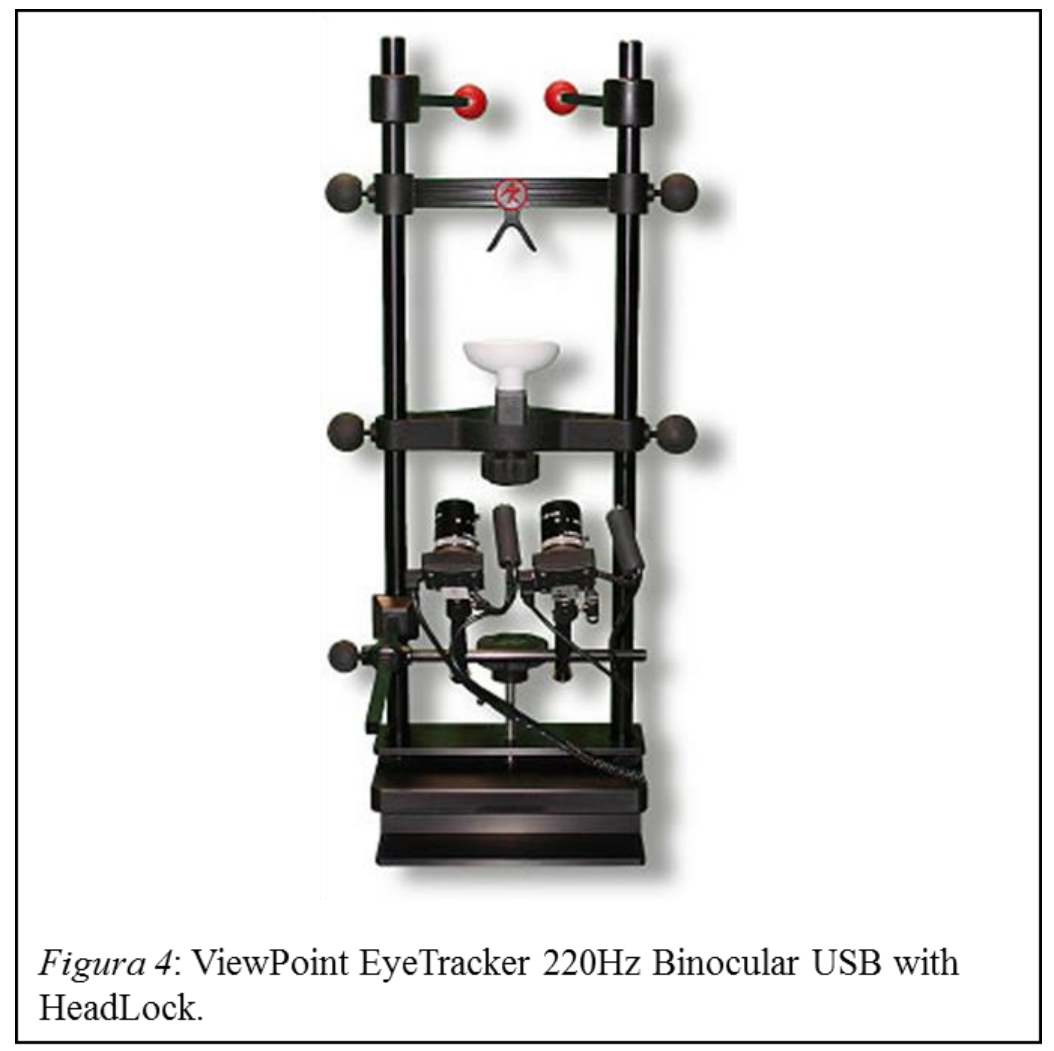

\section{Estímulos}

Para os estímulos de própria face, optou-se pela utilização de fotografias, pela fácil implementação técnica e padronização com os demais estímulos.

Todas as imagens foram tiradas de frente (angulação $0^{\circ}$ ), convertidas para escala de cinzas e padronizadas em resolução, bem como em termos de expressão emocional, adotando- 
se uma expressão emocional neutra. Para os estímulos de própria face, o participante foi instruído a manter uma expressão neutra durante a obtenção da imagem.

Para os estímulos de face não familiar, foram usadas imagens do banco de expressões faciais NimStim (Tottenham et al., 2009).

Todos os estímulos foram apresentados com cabelo, uma vez que o cabelo compõe um dos atributos externos à face durante o processamento e a presença do mesmo não afeta significativamente o reconhecimento da face (Toseeb, Keeble \& Bryant, 2012), uma vez que os atributos internos da face são determinantes no reconhecimento (Frowd, Bruce, McIntyre \& Hancock, 2007; Ellis, Shepherd \& Davies, 1979).

De modo a preservar o sigilo dos participantes bem como evitar a exposição das imagens do banco NimStim, foi criada uma face a partir da média das faces não familiares do banco NimStim. Essa face artificial será utilizada para ilustrar quaisquer estímulos de face utilizados durante a pesquisa, embora essa face não tenha sido apresentada aos participantes.

\section{Procedimento}

Foram utilizados grupos de alunos de graduação e pós-graduação da Universidade de Brasília. A coleta foi feita em duas sessões, para cada grupo.

Os grupos foram organizados de modo a terem 11 participantes. Dessa forma, para cada participante, as faces dos outros 10 participantes do grupo seriam as faces familiares.

$\mathrm{Na}$ primeira sessão, realizada com o grupo todo, inicialmente foi feita uma breve apresentação do estudo a ser realizado. Em seguida, eram apresentados os Termo de consentimento livre e esclarecido (Anexo 1), bem como um Termo de autorização de uso de imagem (Anexo 2), necessários para a participação na pesquisa. Após a assinatura dos termos, era aplicada uma dinâmica de apresentação ao grupo, cujo propósito é garantir que os participantes estejam familiarizados com as faces uns com os outros. Após a aplicação da 
dinâmica, foram agendadas sessões individuais para a coleta de dados com cada participante e foram coletadas as fotos a serem utilizadas como estímulos de própria face. A primeira sessão teve duração média de 30 minutos para cada grupo.

Após a coleta das fotos dos participantes, as fotos eram convertidas em escala de cinzas e normalizadas em níveis de brilho e contraste.

O tempo entre as sessões foi controlado, de modo que, para um dado participante, o intervalo entre a primeira e a segunda sessões fosse, no mínimo $24 \mathrm{~h}$ e inferior à $120 \mathrm{~h}$. O intervalo mínimo de $24 \mathrm{~h}$ foi necessário para a preparação dos estímulos.

Na segunda sessão foi feita a coleta individual dos dados de rastreamento ocular com o eye-tracker. Inicialmente, eram aplicadas as escalas Beck e um questionário (Anexo 3) a cada participante. Em seguida, cada participante se sentava de frente para a tela de apresentação e era instruído a se acomodar no apoio de queixo, distante $65 \mathrm{~cm}$ da tela de apresentação. Era feita então o processo de calibração do aparelho e posterior apresentação dos estímulos e registro dos dados. Os estímulos foram apresentados em uma resolução de 1280 por 768 pixels, e de modo a se aproximar de uma condição real de interação social, os estímulos foram ajustados para que correspondessem à $10^{\circ}$ de ângulo visual no sentido vertical. A apresentação consistia em: tela branca com duração de 2s; cruz de fixação fora da área da face, com duração de $2 \mathrm{~s}$, de modo a evitar um efeito crossover de uma imagem para a outra; estímulo de face, com duração de 1500ms. A apresentação dos estímulos consiste em uma tarefa passiva, isto é, sem a produção de resposta pelo participante.

O tempo total da apresentação dos estímulos por participante foi aproximadamente 90 s. A Figura 5 ilustra o desenho experimental da pesquisa. 


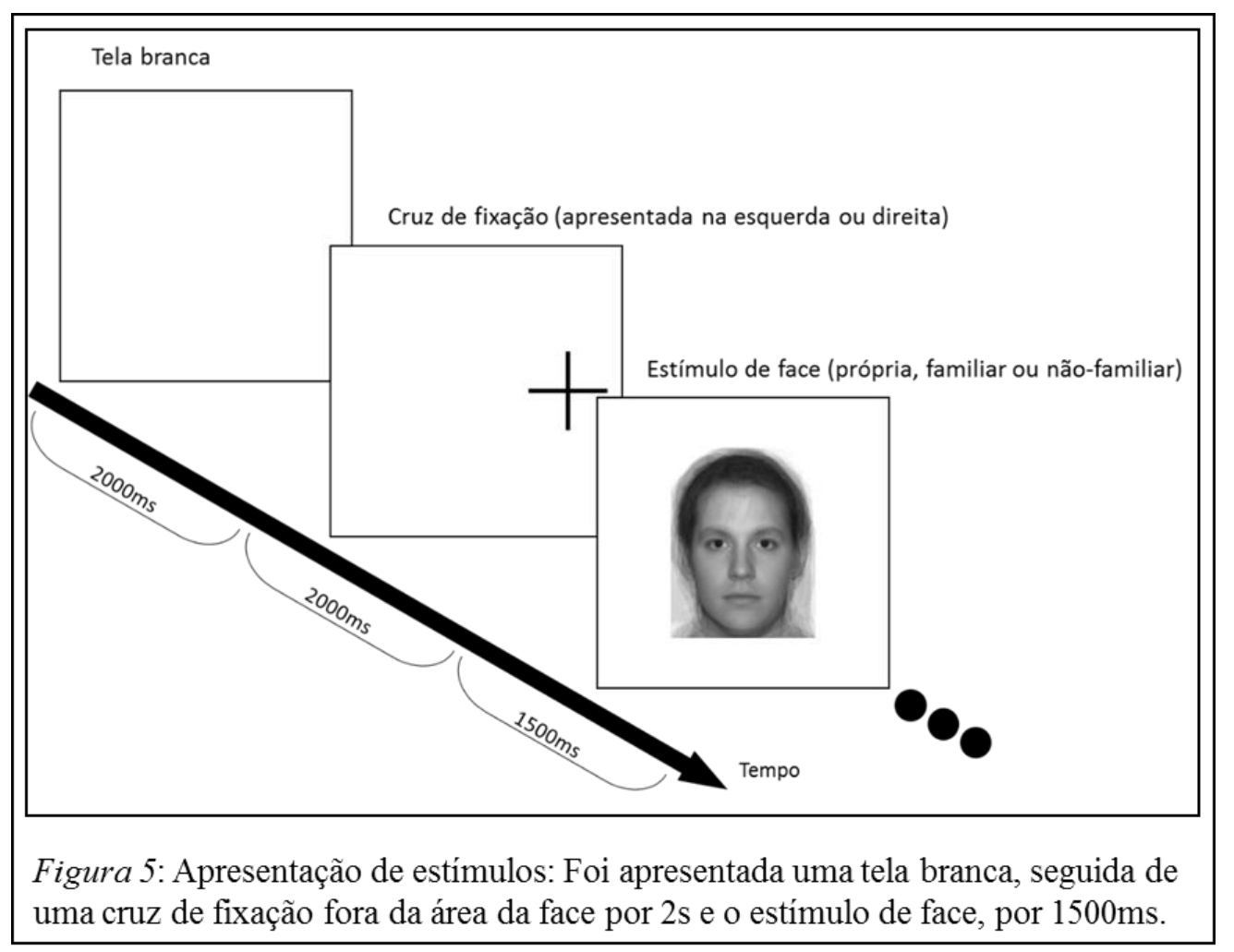

Os estímulos apresentados dividem-se em três grupos: "faces familiares", "faces não familiares" e "própria face". As imagens foram organizadas em uma apresentação randomizada contendo 25 estímulos, sendo 10 estímulos de faces familiares, 10 estímulos de faces não familiares e 5 estímulos de própria face. A Tabela 1 apresenta a descrição dos grupos de estímulos, bem como sua distribuição na apresentação.

\section{Tabela 1}

Descrição dos grupos de estímulos e sua distribuição.

\begin{tabular}{lll}
\hline Grupo & Descrição & Distribuição na apresentação \\
\hline Faces familiares & Faces conhecidas aos participantes & 10 \\
Faces não familiares & Faces não conhecidas aos participantes & 10 \\
Própria face & Faces dos próprios participantes & 5 \\
& & \\
\hline
\end{tabular}




\section{Análise de dados}

As análises iniciais e identificação de eventos visuais (sacadas e fixações) foram feitas através do software ViewPoint. Análises posteriores foram por meio do MATLAB versão R2013a e R Statistics versão 3.2.3.

Para se comparar as sequências de rastreamento visual, foi utilizado o método ScanMatch (Cristino, Mathôt, Theeuwes \& Gilchrist, 2010), que implementa o algoritmo de Needleman-Wunsch (Needleman \& Wunsch, 1970).

O algoritmo de Needleman-Wunsch é baseado na medida da distância de Levenshtein (Levenshtein, 1966), inicialmente utilizada para se medir a semelhança entre duas sequências genéticas. Quando aplicado à uma sequência de fixações visuais, o método de Levenshtein transforma a sequência de coordenadas visuais em uma sequência de caracteres, com base em uma máscara quadriculada, onde cada setor corresponde à um caractere. A Figura 6 ilustra um exemplo de sequência de fixações transformada em sequência de caracteres. Duas sequências podem, então, ser comparadas e se obtém um índice representativo da distância de Levenshtein, que pode ir de 0 (quando não há semelhança alguma, ou 0\%) à 1 (quando as sequências são idênticas, ou 100\%).

O algoritmo de Needleman-Wunsch oferece um método mais robusto de análise de sequências visuais, pois considera também o tempo de duração das fixações, na conversão da sequência de caracteres.

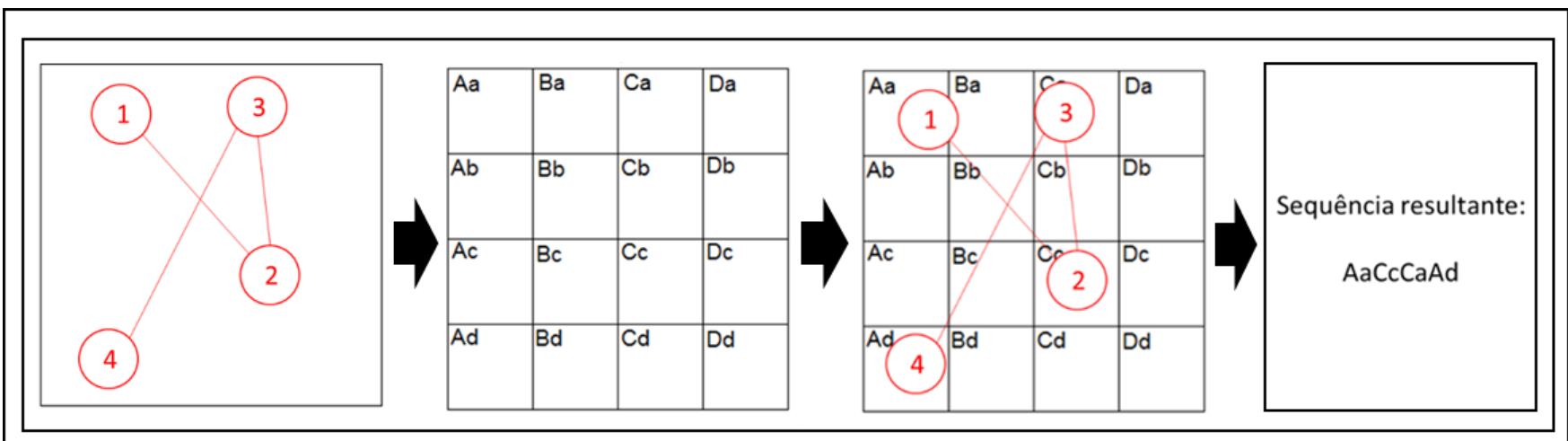

Figura 6: Conversão de uma sequência de fixações em uma sequência de caracteres pela aplicação de uma máscara, no método de Levenshtein. 


\section{Resultados}

Foram estabelecidas 4 regiões de interesse em cada estímulo (ROIs), sendo essas: olho esquerdo (OE), olho direito (OD), nariz (NZ) e boca (BC). Para a análise dos dados de rastreamento ocular, um evento de fixação foi definido como um período contínuo de, no mínimo, 100ms em uma área de $1^{\circ}$ de ângulo visual (Van der Geest, Kemner, Verbaten \& Van Engeland, 2002). Para considerações estatísticas, foi considerado um nível de significância $\alpha$ de 0,05 .

Inicialmente, foi feita uma análise por categoria, a fim de avaliar se há um padrão na visualização de faces de mesmo grau de familiaridade. A categoria de faces próprias, no entanto, é composta por 5 faces iguais. Para avaliar se a utilização das 5 faces próprias por participante incorreria em possível erro metodológico, realizou-se uma análise da categoria de face própria. Realizou-se um teste $t$ de comparação entre as médias dos tempos de fixação por face, onde foi encontrada uma diferença significativa $(p=0,01)$ entre as médias da primeira face, quando comparada com as demais faces. As outras faces não apresentaram diferenças significativas quando comparadas entre si. Com base nesse achado, apenas a primeira face própria de cada participante foi considerada para análise.

Para a análise por categoria, todos os participantes foram comparados uns com os outros em todas as combinações possíveis e foi feita uma média dos índices encontrados, com base no algoritmo de Needleman-Wunsch. Para as faces familiares, não-familiares e próprias, foram encontrados índices de $0,65,0,70$ e 0,74 , respectivamente.

Quando comparadas as médias dos tempos de fixação por teste ANOVA de fator único (325ms para faces familiares, 333ms para faces não-familiares e 319ms para faces próprias), não foi observada nenhuma diferença significativa entre as categorias $(p=0,80 ; f=0,23)$.

Para avaliar as diferenças entre as categorias, foram criadas sequências compostas pelas sequências de todos os participantes, de modo que foram comparadas 3 grandes sequências, 
sendo uma de cada categoria. Além disso, as categorias foram comparadas por número de fixações, uma vez que à medida que são feitas mais fixações, os padrões de rastreamento tendem a ser diferentes em faces de diferentes graus de familiaridade (Van Belle, Ramon, Lefèvre \& Rossion, 2010), ilustrado na Figura 7.

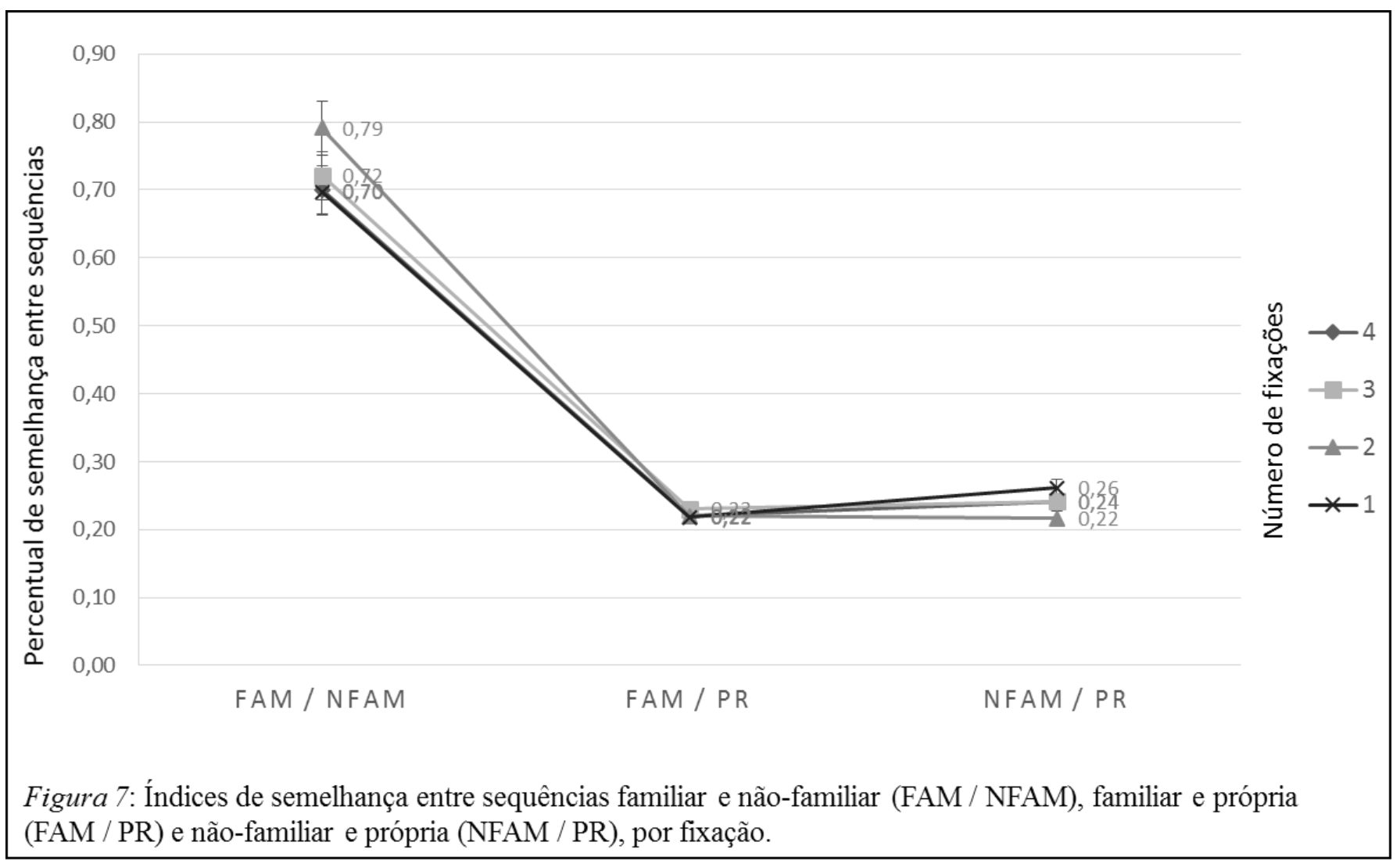

Como mostra o gráfico da Figura 7, as sequências referentes às faces familiares e não familiares são mais semelhantes do que as demais comparações, independente do número de fixações.

Para construir o gráfico da Figura 7, foram feitas comparações entre as sequências (FAM / NFAM; FAM / PR e NFAM / PR) para quatro, três, duas e uma fixação. As comparações feitas por meio do método ScanMatch (Cristino et al., 2010) estão ilustradas no Anexo 4.

As posições das fixações também foram analisadas. A despeito do lado de apresentação da cruz de fixação, a localização da primeira fixação dentro da área da face era na área central 
da face, para todas as categorias. Embora não tenha sido possível produzir mapas de calor, a Figura 8 ilustra a dispersão das fixações, levando em consideração o tempo de fixação, para cada categoria de estímulo.

A Figura 8 mostra as médias de dispersão por categoria. Nota-se que para as faces familiares e não familiares, a dispersão está concentrada no centro geométrico da face. Nas faces próprias, observa-se um padrão menos concentrado, com fixações mais curtas no geral.

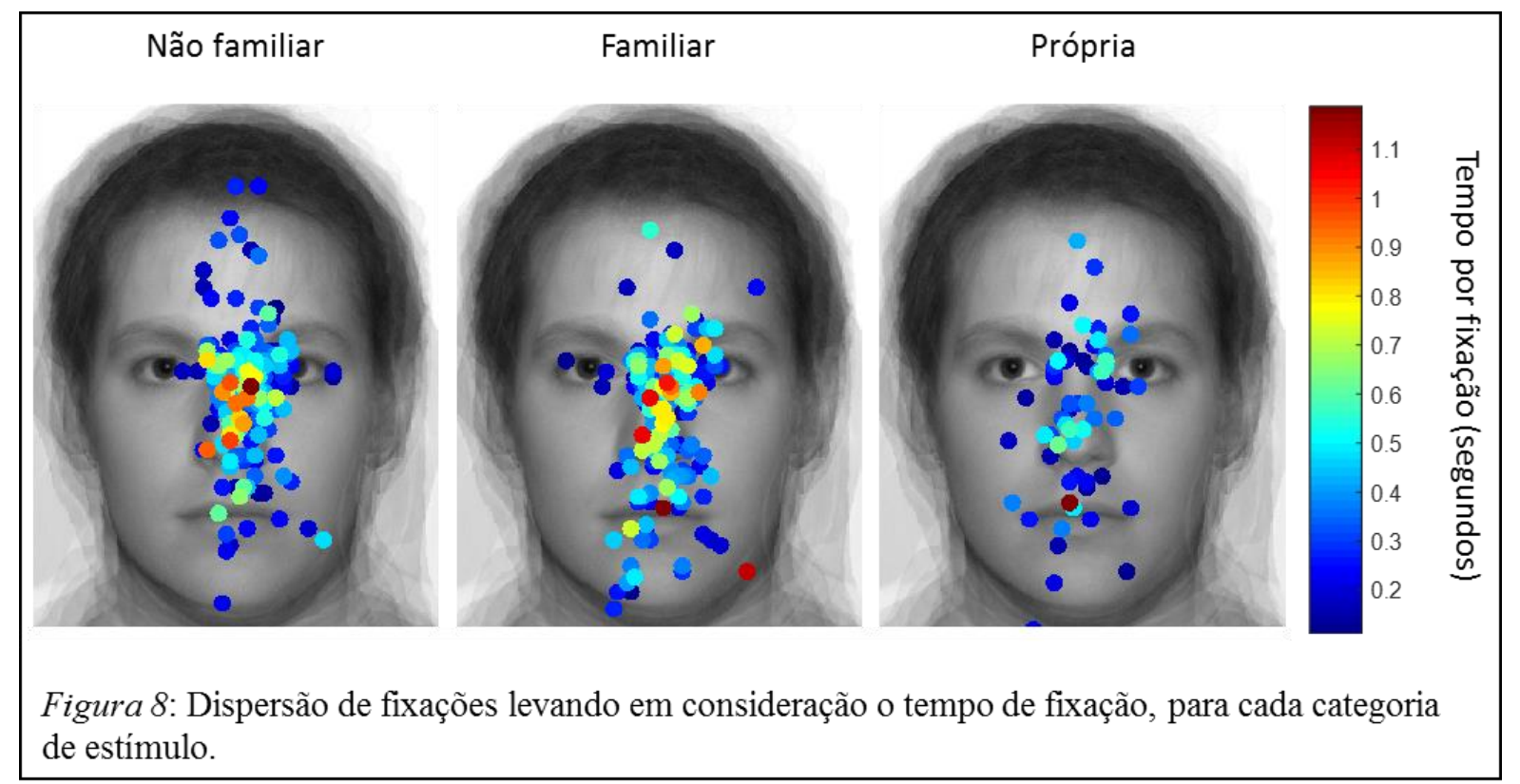

Também foi feita uma análise por ROI, considerando a porcentagem de tempo passada em cada ROI, em relação ao tempo total passado na face. Foi observada uma diferença significativa tanto no número de fixações, quanto no tempo de fixação, para a ROI do olho esquerdo $(37,4 \%, 34,9 \%$ e $39 \%$ para faces familiares, não familiares e próprias, respectivamente), quando comparada com as ROIs do olho direito (20,7\%, $25 \%$ e $26,1 \%)$, nariz $(32,4 \%, 31,6 \%$ e $24,1 \%)$ e boca $(9,4 \%, 8,6 \%$ e 10,8\%). Na análise de ROI por categoria, não foi observada diferença significativa em nenhuma das ROIs. A Figura 9 ilustra a análise por ROIs. 


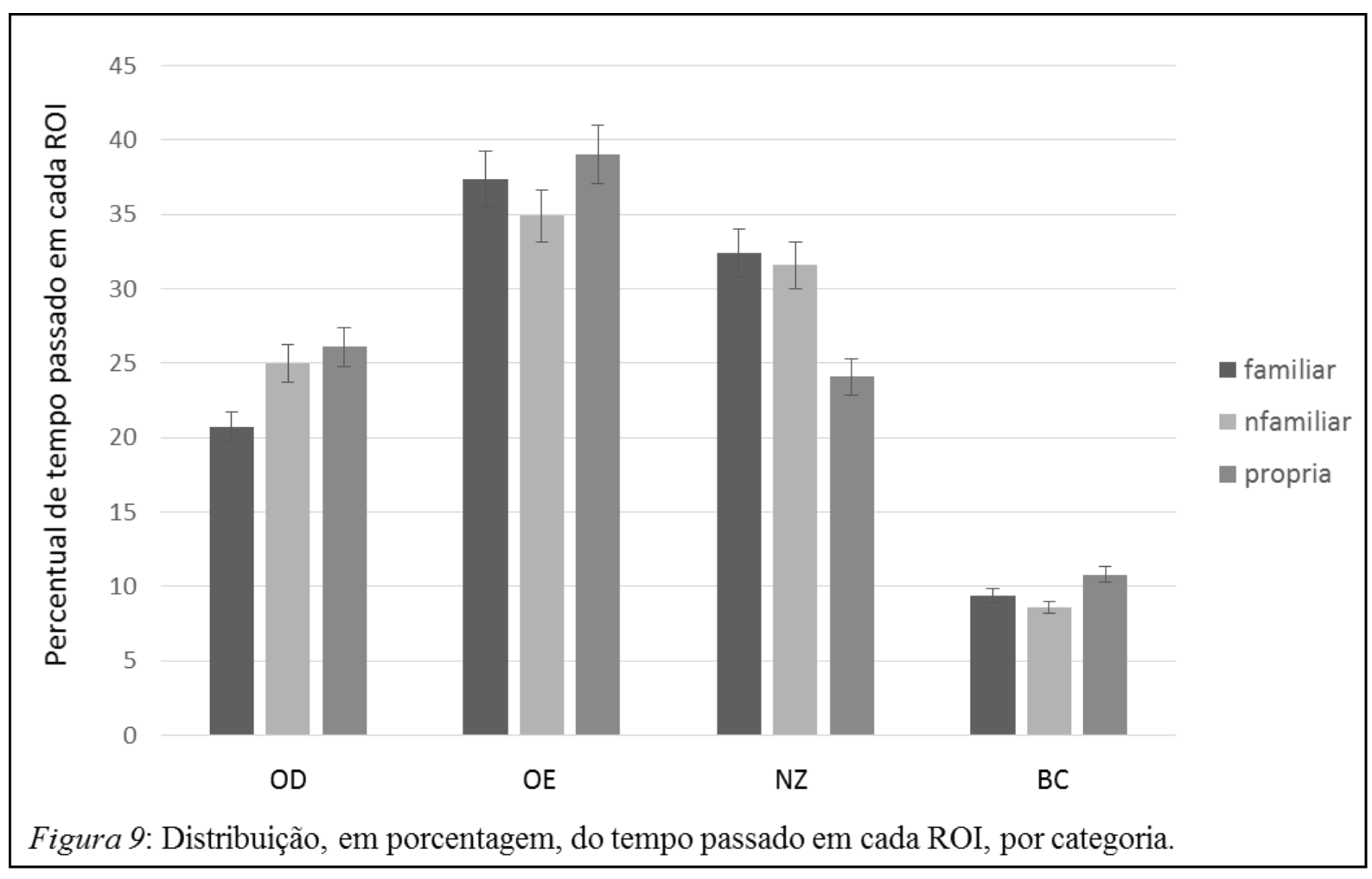




\section{Discussão}

A presente pesquisa teve como objetivo, comparar o padrão de rastreamento visual de faces em diferentes graus de familiaridade. Para tanto, buscou-se avaliar se há um padrão em cada categoria de face, tendo como base elementos dos estudos de Van Belle et al. (2010) e Kita et al. (2010), para montar uma metodologia capaz de satisfatoriamente investigar os objetivos estabelecidos.

Os dados apresentados nos resultados permitem concluir que a hipótese inicial da presente pesquisa é correta. Não há diferença no padrão de rastreamento visual de faces em diferentes graus de familiaridade. Há de se ressaltar, porém, que essa conclusão se aplica para o rastreamento até as quatro primeiras fixações. A restrição feita às quatro primeiras fixações, foi feita pois as quatro primeiras fixações representam a coleta das informações essenciais para o reconhecimento de uma face.

Para todas as categorias de estímulo, nota-se que a localização da primeira fixação corresponde ao centro geométrico da face. De acordo com Hisao e Cottrell (2008), a primeira fixação é essencial para a aquisição da informação visual necessária para o reconhecimento de uma face. A escolha dessa localização não parece sofrer influência de tarefa ou de cultura, o que reforça as evidências de uma visualização holística para faces (Orban de Xivry, Ramon, Lefèvre \& Rossion, 2008; Rodger, Blais \& Caldara, 2010; Peterson \& Eckstein, 2012; Or, Peterson \& Eckstein, 2015).

Devue, Stigchel, Brédart e Theeuwes (2009) apontam para a face própria como um estímulo que toma prioridade sobre outros em tarefas de busca, inclusive sobre faces familiares. Poderia se esperar, portanto, maiores tempos de fixação para faces próprias. No entanto, tal efeito não foi observado.

A comparação entre a visualização de faces próprias, faces familiares e faces não familiares, apresentada pela presente pesquisa, sustenta o processamento holístico de faces. 
Uma das diferenças da presente pesquisa, com relação às pesquisas existentes na literatura, é o uso das fotografias dos próprios participantes como estímulos de face própria. Muitas pesquisas utilizam fotos de faces de pessoas famosas como faces familiares. No entanto, tem se proposto que faces famosas devem ser consideradas uma categoria à parte, pois, além de um processamento neural diferente de faces familiares (Baird \& Burton, 2008), o efeito de familiaridade pode ser devido à outros elementos presentes na foto, tais como pose e não à face em si.

A análise de padrões de rastreamento visual por comparação de sequências de caracteres oferece uma metodologia alternativa para estudos com eye-tracking. Embora existam críticas relativas à análise de dados de rastreamento visual por meio da comparação de sequências, utilizando algoritmos que podem introduzir ruído nos dados por não considerarem a duração das fixações, essa análise teria sido considerada satisfatória e suficiente para os objetivos da presente pesquisa. No entanto, de modo a eliminar esse problema, optou-se pelo uso do algoritmo de Needleman-Wunsch. Tal algoritmo considera a duração das fixações para criar as sequências a serem comparadas, o que ajuda a tornar as sequências robustas e representativas dos dados, quando analisados por outros métodos.

O efeito de outra etnia (other-race effect) diz respeito a uma possível queda de performance em tarefas de reconhecimento de faces quando são apresentadas faces de pessoas de uma etnia diferente da etnia do participante (Lindsay, Jack \& Christian, 1991). As explicações para tal efeito podem ser de cunho social ou cognitivo-perceptual. A teoria social propõe que são ativadas categorias étnicas durante o reconhecimento da face relacionadas à estereotipação de características consideradas típicas de um grupo étnico. Já a teoria cognitivaperceptual, sugere que podem haver diferenças entre etnias no que diz respeito à sinais perceptuais de identificação de faces individuais. No entanto, estudos tem mostrado que a exposição contínua a faces de outra etnia, tal como viver em uma cultura miscigenada, bem como o grau de familiaridade com a face, podem diminuir ou eliminar o efeito de outra etnia 
(Marcon, Susa \& Meissner, 2009; Yonelinas, 2002). Assim, é possível que as teorias que explicam o efeito de outra etnia não sejam mutuamente excludentes.

Semelhante ao efeito de outra raça, foi mostrado que há uma queda de performance no reconhecimento de faces de pessoas em outras faixas etárias (other-age effect). O efeito de idade foi mostrado em crianças, quando observando faces de adultos, e em jovens adultos, quando observando faces mais velhas, mas não em adultos observando faces mais jovens, o que sugere que o efeito de idade pode ter relação com a experiência com faces de um certo grupo etário (Kuefner, Macchi Cassia, Picozzi \& Bricolo, 2008; Ebner et al., 2013).

$\mathrm{Na}$ presente pesquisa, possivelmente devido ao tamanho da amostra, não foram observados efeitos de idade ou raça. Assim, essas variáveis não foram analisadas. 


\section{Conclusão}

A presente pesquisa permitiu concluir que: 1) os participantes tendem a realizar o rastreamento visual de faces familiares de modo semelhante; 2) os participantes tendem a realizar o rastreamento visual de faces não familiares de modo semelhante; 3) os participantes tendem a realizar o rastreamento visual de faces próprias de modo semelhante. Além disso, foi possível observar que o padrão observado para faces familiares foi semelhante ao observado para faces não familiares.

A aparente discrepância entre faces próprias e as demais categorias pode ser devido à uma falha metodológica da pesquisa. Uma vez que se considerou apenas uma face própria por participante, a diminuição de dados desta categoria pode ter influenciado as comparações com as demais categorias, exagerando diferenças na comparação das sequências. Também é possível que a discrepância se dê pela natureza do estímulo de face própria.

Apesar dos equipamentos de rastreamento ocular tenderem à uma acessibilidade cada vez maior, os métodos de análise para esse tipo de dado permanecem de difícil acesso, especialmente para pequenos grupos de pesquisa ou pesquisadores inexperientes. No entanto, métodos de análise como os descritos na presente pesquisa - medidas de distância de Levenshtein por algoritmos como os de Needleman-Wunsch, dispersão de fixações - permitem a realização de estudos robustos, com resultados equiparáveis à estudos realizados por grandes grupos de pesquisa.

Embora a presente pesquisa não tenha identificado efeitos de idade ou raça na amostra utilizada, um estudo subsequente, com uma amostra ampliada, poderia esclarecer os problemas da discrepância das faces próprias, bem como considerar possíveis efeitos de raça e idade como variáveis no rastreamento das faces.

Vale ressaltar que, embora os resultados obtidos na comparação dos padrões de rastreamento visual sejam relativamente semelhantes aos apresentados em outros estudos, a 
comparação entre os níveis de familiaridade dos participantes de um grupo com outro grupo, isto é, se os participantes de um grupo eram mais familiares do que os participantes de outro grupo, não foi explorada. A inclusão dessa comparação poderia ocorrer em uma pesquisa subsequente. 


\section{Referências Bibliográficas}

Amsterdam, B. (1972). Mirror self-image reactions before age two. Developmental Psychobiology. 5(4): 297-305.

Armstrong, T., \& Olatunji, B. O. (2012). Eye tracking of attention in the affective disorders: a meta-analytic review and synthesis. Clinical Psychology Review. 32(8): 704-23.

Baird, L. M., \& Burton, A. M. (2008). The bilateral advantage for famous faces: Interhemispheric communication or competition? Neuropsychologia. 46(5): 1581-7.

Bandura, A. (1988). Organizational Application of Social Cognitive Theory. Australian Journal of Management. 13(2): 275-302.

Bandura, A. (1989). Human Agency in Social Cognitive Theory. American Psychologist. 44(9): $1175-84$

Barreto, A. M. (2012). Eye tracking como método de investigação aplicado às ciências da comunicação. Revista Comunicando. 1(1).

Barrett, H. C. (2008). Evolved cognitive mechanisms and human behavior. In Crawford, C. \& Krebs, D. (eds.) Foundations of evolutionary psychology: Ideas, issues, applications and findings. (2a ed.) Mahwah, NJ: Erlbaum Associates, 173-190.

Bear, M. F., Connors, B. W., \& Paradiso, M. A. (2008). Neurociências: Desvendando o sistema nervoso. (3a ed.) Porto Alegre, Artmed. 
Biederman, I., \& Kalocsai, P. (1997). Neurocomputational bases of object and face recognition. Phil. Trans. R. Soc. Lond. 352(1358): 1203-19.

Brédart, S., Delachambre, M., \& Laureys, S. (2006). One's own face is hard to ignore. Quarterly Journal of Experimental Psychology. 59(1): 46-52.

Bruce, V. (1982). Changing faces: Visual and non-visual coding processes in face recognition. British Journal of Psychology. 73(1): 105-16.

Bruce, V. (1986). Influences of familiarity on the processing of faces. Perception. 15(4): 38797.

Bruce, V., \& Young, A. (1986). Understanding face recognition. British Journal of Psychology. 77(3): 305-27.

Burke, D., \& Sulikowski, D. (2013). The evolution of holistic processing of faces. Frontiers in Psychology. 4(11).

Butler, D. L., Mattingley, J. B., Cunnington, R., \& Suddendorf, T. (2012). Mirror, mirror on the wall, how does my brain recognize my image at all? PLoS ONE. 7(2): e31452.

Chen, N. T., Thomas, L. M., Clarke, P. J., Hickie, I. B., \& Guastella, A. J. (2015). Hyperscanning and avoidance in social anxiety disorder: the visual scanpath during public speaking. Psychiatry Research. 225(3):667-72. 
Cristino, F., Mathôt, S., Theeuwes, J., \& Gilchrist, I. (2010). ScanMatch: A novel method for comparing fixation sequences. Behavior Research Methods. 42(3): 692-700.

Cunha, J. (2001). Manual em português das Escalas Beck. São Paulo: Casa do Psicólogo.

Darwin, C. (2009). A expressão das emoções no homem e nos animais. São Paulo: Companhia das Letras.

DeAngelus, M., \& Peltz, J.B. (2009). Top-down control of eye movements: Yarbus revisited. Visual Cognition. 17(6-7): 790-811.

Devue, C., \& Brédart, S. (2011). The neural correlates of visual self-recognition. Consciousness and Cognition. 20(1): 40-51.

Devue, C., Collette, F., Balteau, E., Degueldre, C., Luxen, A., Maquet, P., \& Brédart, S. (2007). Here I am: The cortical correlates of visual self-recognition. Brain Research. 1143: 169-182.

Devue, C., Van der Stigchel, S., Brédart, S., \& Theeuwes, J. (2009). You do not find your own face faster; you just look at it longer. Cognition. 111(1): 114-22.

De Souza, W. C., Feitosa, M. A. G., Eifuku, S., Tamura, R., \& Ono, T. (2008). Face perception in its neurobiological and social context. Psychology \& Neuroscience. 1(1): 15-20.

Diamond, R., \& Carey, S. (1986). Why faces are and are not special: an effect of expertise. Journal of Experimental Psychology General. 115(2): 107-17. 
Duchowski, A. (2006). Eye tracking methodology: Theory and practice. (2a ed.) Clemson: Springer.

Ebner, N. C., Johnson, M. R., Rieckmann, A., Durbin, K. A., Johnson, M. K., \& Fischer, H. (2013). Processing own-age vs. other-age faces: Neuro-behavioral correlates and effects of emotion. Neuroimage. 78:363-71.

Eifuku, S., De Souza, W. C., Nakata, R., Ono, T., \& Tamura, R. (2011). Neural Representations of Personally Familiar and Unfamiliar Faces in the Anterior Inferior Temporal Cortex of Monkeys. PLoS ONE. 6(4), e18913.

Eifuku, S., De Souza, W. C., Tamura, R., Nishijo, H., \& Ono, T. (2003). On the organization of face memory. International Congress Series. 1250: 73-85.

Ellis, H. D., Shepherd, J. W., \& Davies, G. M. (1979). Identification of familiar and unfamiliar faces from internal and external features: some implications for theories of face recognition. Perception. 8(4): 431-9.

Field, T. M., Cohen, D., Garcia, R., \& Greenberg, R. (1984). Mother-stranger face discrimination by the newborn. Infant Behavior and Development. 7(1): 19-25.

Frowd, C., Bruce, V., McIntyre, A., \& Hancock, P. (2007). The relative importance of external and internal features of facial composites. British Journal of Psychology. 98(1): 61-77. 
Greenberg, S. N., \& Goshen-Gottstein, Y. (2009). Not all faces are processed equally: Evidence for featural rather than holistic processing of one's own face in a face-imaging task. Journal of Experimental Psychology General. 35(2): 499-508.

Gobbini, M. I., \& Haxby, J. V. (2006). Neural response to the visual familiarity of faces. Brain Research Bulletin. 71(1-3): 76-82.

Gobbini, M. I., \& Haxby, J. V. (2007). Neural systems for recognition of familiar faces. Neuropsychologia. 45(1): 32-41.

Haxby, J. V., Hoffman, E. A., \& Gobbini, M. I. (2000). The distributed human neural system for face perception. Trends in Cognitive Sciences. 4(6): 223-233.

Haxby, J. V., Gobbini, M. I., Furey, M. L., Ishai, A., Schouten, J. L., \& Pietrini, P. (2001). Distributed and overlapping representations of faces and objects in ventral temporal cortex. Science. 293(5539): 2425-30.

Haxby, J. V., Hoffman, E. A., \& Gobbini, M. I. (2002). Human Neural Systems for Face Recognition and Social Communication. Biological Psychiatry. 51(1): 59-67.

Holmqvist, K., Nyström, M., Andersson, R., Dewhurst, R., Jarodzka, H., \& Weijer, J. van de. (2011). Eye-tracking: A comprehensive guide to methods and measures. Oxford: Oxford University Press.

Hsiao, J. H., \& Cottrell, G. (2008). Two fixations suffice in face recognition. Psychological Science. 19(10): 998-1006. 
Ishai, A. (2008). Let's face it: It's a cortical network. NeuroImage. 40(2), 415-9.

Ishai, A., Schmidt, C. F., \& Boesiger, P. (2005). Face perception is mediated by a distributed cortical network. Brain Research Bulletin. 67(1-2): 87-93.

Johnston, R. A., \& Edmonds, J. A. (2009). Familiar and unfamiliar face recognition: a review. Memory. 17(5): 577-96.

Kanwisher, N., \& Yovel, G. (2006). The fusiform face area: a cortical region specialized for the perception of faces. Philosophical Transactions of the Royal Society B. 361(1476): 2109-2128.

Kanwisher, N., McDermott, J., \& Chun, M. M. (1997). The fusiform face area: a module in human extrastriate cortex specialized for face perception. Journal of Neuroscience. 17(11): 4302-11.

Keenan, J. P., Wheeler, M. A., Gallup, G. G. Jr., \& Pascual-Leone, A. (2000). Self-recognition and the right pre-frontal cortex. Trends in Cognitive Sciences. 4(9): 338-344.

Kita, Y., Gunji, A., Sakihara, K., Inagaki, M., Kaga, M., Nakagawa, E., \& Hosokawa, T. (2010). Scanning strategies do not modulate face identification: Eye-tracking and near-infrared spectroscopy study. PLoS ONE. 5(6): e11050.

Kuefner, D., Macchi Cassia, V., Picozzi, M., \& Bricolo, E. (2008). Do all kids look alike? Evidence for an other-age effect in adults. Journal of Experimental Psychology. Human perception and performance. 34(4):811-7. 
Levenshtein, V. (1966). Binary codes capable of correcting deletions, insertions, and reversals. Soviet Physics-Doklady. 10(8): 707-710.

Levy, D. L., Sereno, A. B., Gooding, D. C., \& O’Driscoll, G. A. (2010). Eye tracking dysfunction in schizophrenia: characterization and pathophysiology. Current Topics in Behavioral Neurosciences. 4:311-47.

Li, J., Liu, J., Liang, J., Zhang, H., Zhao, J., Huber, D. E., ... Shi, G. (2009). A distributed neural system for top-down face processing. Neuroscience Letters. 451(1): 6-10.

Lindsay, D. S., Jack, P. C. Jr., \& Christian, M. A. (1991). Other-race face perception. Journal of Applied Psychology. 76(4): 587-9.

Malcolm, G. L., \& Henderson, J. M. (2010). Combining top-down processes to guide eye movements during real-world scene search. Journal of Vision. 10(2): 4.1-11.

Marcon, J.L., Susa, K.J., \& Meissner, C.A. (2009). Assessing the influence of recollection and familiarity in memory for own- versus other-race faces. Psychonomic Bulletin \& Review. 16(1): 99-103.

Martinez-Conde, S., Macknik, S.L., \& Hubel, D. H. (2004). The role of fixational eye movements in visual perception. Nature Reviews Neuroscience. 5(3): 229-40.

McCarthy, G., Luby, M., Gore, J., \& Goldman-Rakic, P. (1997). Infrequent events transiently activate human prefrontal and parietal cortex as measured by functional MRI. Journal of Neurophysiology. 77(3): 1630-4. 
McKone, E. M., \& Robbins, R. R. (2010). In The Handbook of Face Perception, Are faces special? ed Calder, A. C., et al. Oxford: Oxford University Press.

Morton J., \& Johnson, M. (1991). CONSPEC and CONLEARN: A two-process theory of infant face recognition. Psychological Review. 98(2): 164-81.

Needleman, S.B., \& Wunsch, C.D. (1970). A general method applicable to the search for similarities in the amino acid sequence of two proteins. Journal of Molecular Biology. 48(3): 443-53.

Neisser, U. (2014). Cognitive psychology. New York: Appleton-Century-Crofts.

Nummenmaa, L., Hyönä, J., \& Calvo. M. G. (2006). Eye movement assessment of selective attentional capture by emotional pictures. Emotion. 6(2): 257-68.

Or, C. C.-F., Peterson, M. F., \& Eckstein, M. P. (2015). Initial eye movements during face identification are optimal and similar across cultures. Journal of Vision. 15(13): 12.

Orban de Xivry, J. J., Ramon, M., Lefèvre, P., \& Rossion, B. (2008). Reduced fixation on the upper area of personally familiar faces following acquired prosopagnosia. Journal of Neuropsychology. 2(1): 245-68.

Parr, L. A. (2014). The evolution of face processing in primates. Philosophical Transactions of the Royal Society of London Series B, Biological sciences. 366(1571): 1764-77. 
Peterson, M. F., \& Eckstein, M. P. (2012). Looking just below the eyes is optimal across face recognition tasks. Proceedings of the National Academy of Sciences of the United States of America. 109(48): E3314-23.

Platek, S. M., Wathne, K., Tierney, N. G., \& Thomson, J. W. (2008). Neural correlates of selfface recognition: An effect-location meta-analysis. Brain Research. 1232: 173-84.

Rodger, H., Blais, C., \& Caldara, R. (2010). First fixation toward the geometric center of human faces is common across tasks and culture. Journal of Vision. 10(7): 639.

Schiffman, H. R. (2005). Sensação e percepção. Rio de Janeiro: LTC.

Schulze, L., Renneberg, B., \& Lobmaier, J. S. (2013). Gaze perception in social anxiety and social anxiety disorder. Frontiers in Human Neuroscience. 3:872.

Tatler, B. W., \& Vincent, B. T. (2008). Systematic tendencies in scene viewing. Journal of Eye Movement Research. 2(2):5, 1-18.

Toh, W. L., Rossell, S. L., \& Castle, D. J. (2011). Current visual scanpath research: a review of investigations into the psychotic, anxiety, and mood disorders. Comprehensive Psychiatry. 52(6): 567-79.

Tong, F., \& Nakayama, K. (1999). Robust representations for faces: Evidence from visual search. Journal of Experimental Psychology. 25(4): 1016-35. 
Toseeb, U., Keeble, D. R. T., \& Bryant, E. J. (2012). The significance of hair for face recognition. PLoS ONE. 7(3): e34144.

Tottenham, N., Tanaka, J., Leon, A. C., McCarry, T., Nurse, M., Hare, ... Nelson, C. A. (2009). The NimStim set of facial expressions: judgments from untrained research participants. Psychiatry Research. 168(3): 242-9.

Van Belle, G., Ramon, M., Lefèvre, P. \& Rossion, B. (2010). Fixation patterns during recognition of personally familiar and unfamiliar faces. Frontiers in Psychology. 1: 20.

Van der Geest, J. N., Kemner, C., Verbaten, M. N. \& Van Engeland, H. (2002). Gaze behavior of children with pervasive developmental disorder toward human faces: a fixation time study. $J$ Child Psychol Psychiatry. 43(5): 669-678.

Yarbus, A. L. (1967). Eye movements and vision. New York: Plenum Press.

Yonelinas, A. P. (2002). The nature of recollection and familiarity: A review of 30 years of research. Journal of Memory \& Language. 46(3): 441-517.

Werner, J. S., \& Chalupa, L. M. (2014). The new visual neurosciences. Massachusets: MIT Press. 


\section{Anexo 1}

Termo de Consentimento Livre e Esclarecido

Somos pesquisadores da Universidade de Brasília (UnB), da área de Psicologia. O(a) senhor(a) está sendo convidado(a) a participar de uma pesquisa que investigará o reconhecimento de faces familiares e não familiares.

A pesquisa está dividida em quatro etapas:

1) Leitura e assinatura dos termos de consentimento e de autorização de uso de imagem;

2) Aplicação de questionários de avaliação;

3) Coleta de fotos;

4) Reconhecimento de faces familiares e não familiares.

Essas quatro etapas serão realizadas no laboratório de psicobiologia da UnB. Espera-se que essas etapas ocorram em duas sessões, de aproximadamente uma hora cada.

Todas as informações relacionadas à sua participação serão mantidas em sigilo, na Universidade de Brasília. Seus dados pessoais não serão divulgados em hipótese alguma, salvo sua imagem, que poderá ser exibida em publicações acadêmicas, bem como na apresentação áudio-visual da presente pesquisa. Depois de encerrado, você poderá ter acesso ao trabalho, caso tenha interesse.

Lembramos que a participação nesta pesquisa é voluntária e, a qualquer momento, é possível desistir por qualquer motivo, sem nenhum tipo de prejuízo à você. Caso haja qualquer outra dúvida, o pesquisador pode ser contatado a partir do telefone que consta ao final deste documento. 
Desde já, agradecemos sua confiança e colaboração.

Cordialmente,

Ivan B.F. Grebot

Telefone: (61) 8432-6072
Profa. Dra. Wânia Cristina de Souza

Telefone: (61) 3307-2625, ramal 520

Assinatura do participante

Data: I

Telefone: $(\quad)$

Comitê de Ética em Pesquisa

cep_ih@unb.br

Nome: 


\author{
Anexo 2 \\ Termo de autorização de uso de imagem \\ Pessoa maior de 18 anos
}

Neste ato, e para todos os fins em direito admitidos, autorizo expressamente a utilização da minha imagem, em caráter definitivo e gratuito, constante em fotos decorrentes da minha participação na pesquisa da Universidade de Brasília, a seguir discriminado:

Título do projeto: Padrões de rastreamento na visualização de faces próprias e não próprias Pesquisador: Ivan Bouchardet da Fonseca Grebot Orientadora: Profa. Dra. Wânia Cristina de Souza

As imagens poderão ser exibidas: nos relatórios parcial e final do referido projeto, na apresentação áudio-visual do mesmo, em publicações e divulgações acadêmicas, em festivais e premiações nacionais e internacionais, assim como disponibilizadas no banco de imagens resultante da pesquisa e na Internet, fazendo-se constar os devidos créditos.

O pesquisador fica autorizado a executar a edição e montagem das fotos, conduzindo as alterações que entender necessárias, bem como a produzir os respectivos materiais de comunicação, respeitando sempre os fins aqui estipulados.

Por ser esta a expressão de minha vontade, nada terei a reclamar a título de direitos conexos a minha imagem e voz ou qualquer outro. 
Brasília, de de 20

Assinatura

Nome:

RG.: CPF:

Telefone1: ( ) 


\section{Anexo 3}

Questionário

Nome:

Sexo: ( ) F ( ) M Idade:

Escolaridade:

Instituição afiliada: ( ) UnB

( ) Outra:

Dominância ocular: ( ) Destro

( ) Canhoto

A seguir, por favor leia com atenção e responda as perguntas com sinceridade. Sua identidade e respostas serão mantidas em total sigilo. As informações obtidas por meio deste questionário serão utilizadas apenas para os fins desta pesquisa e não serão compartilhadas com outros pesquisadores.

1. Você dormiu bem na noite anterior?

( ) $\operatorname{Sim}$

( ) Não

2. Você possui histórico de alguma doença psiquiátrica? ( ) Sim ） ( ) Não Se sim, qual(is) diagnóstico(s) melhor se aplicam a você?
( ) Depressão
( ) Episódio depressivo único
( ) Transtorno bipolar
( ) Episódio hipomaníaco
( ) Transtorno de stress pós-traumático
( ) Esquizofrenia
( ) Transtorno de ansiedade generalizada
( ) Fobia
( ) Episódio maníaco
( ) Outra(s):

3. Caso você tenha assinalado a opção "fobia", qual seria a melhor descrição para aquilo que lhe causa medo?
( ) Aranha
( ) Cobra
( ) Fogo
( ) Altura
( ) Violência
( ) Barata
( ) Outros: 
4. Em caso de ter respondido "episódio depressivo único", qual é a data aproximada de ocorrência do mesmo?

Ainda mantém uso de medicação?
( ) $\operatorname{Sim}$
( ) Não

5. Você já apresentou:

$\rightarrow$ Crise convulsiva:

( ) $\operatorname{Sim}$

( ) Não

$\rightarrow$ Epilepsia:

( ) $\operatorname{Sim}$

( ) Não

6. Você apresenta ou apresentou alguma outra condição neurológica?
( ) $\operatorname{Sim}$
( ) Não

Em caso afirmativo, qual?

7. Você faz uso de alguma medicação para tratamento psiquiátrico ou neurológico?
( ) $\operatorname{Sim}$
( ) Não

Em caso afirmativo, qual(is)?

8. Você possui alguma dificuldade visual?
( ) Miopia $\rightarrow$ Grau: OD
$\mathrm{OE}$
( ) Astigmatismo $\rightarrow$ Grau: OD
$\mathrm{OE}$
( ) Hipermetropia $\rightarrow$ Grau: OD
$\mathrm{OE}$
( ) Catarata
( ) Estrabismo
( ) Daltonismo
( ) Glaucoma
( ) Outra(s):

9. Caso tenha alguma dificuldade visual, você usa óculos ou lentes de contato adequados para a mesma?

$$
\text { ( ) } \operatorname{Sim} \quad \text { ( ) Não }
$$

10. Você possui prosopagnosia (dificuldade em reconhecer o rosto das pessoas) ou algum outro tipo de agnosia visual (alterações da percepção visual em geral, como dificuldade para reconhecer formas, cores, texturas, etc.)?
( ) $\operatorname{Sim}$
( ) Não 
11. Como você classificaria seu estado de humor nesse momento (escolha no máximo três alternativas):
( ) Feliz
( ) Angustiado(a) / Preocupado(a)
( ) Calmo(a)
( ) Triste
( ) Irritado(a) / Impaciente
( ) Ansioso(a)
( ) Indiferente
( ) Outro(s)

Declaro, para os devidos fins, que as informações acima são verídicas.

Brasília, de de 20

Assinatura 


\section{Anexo 4}

Comparações ScanMatch
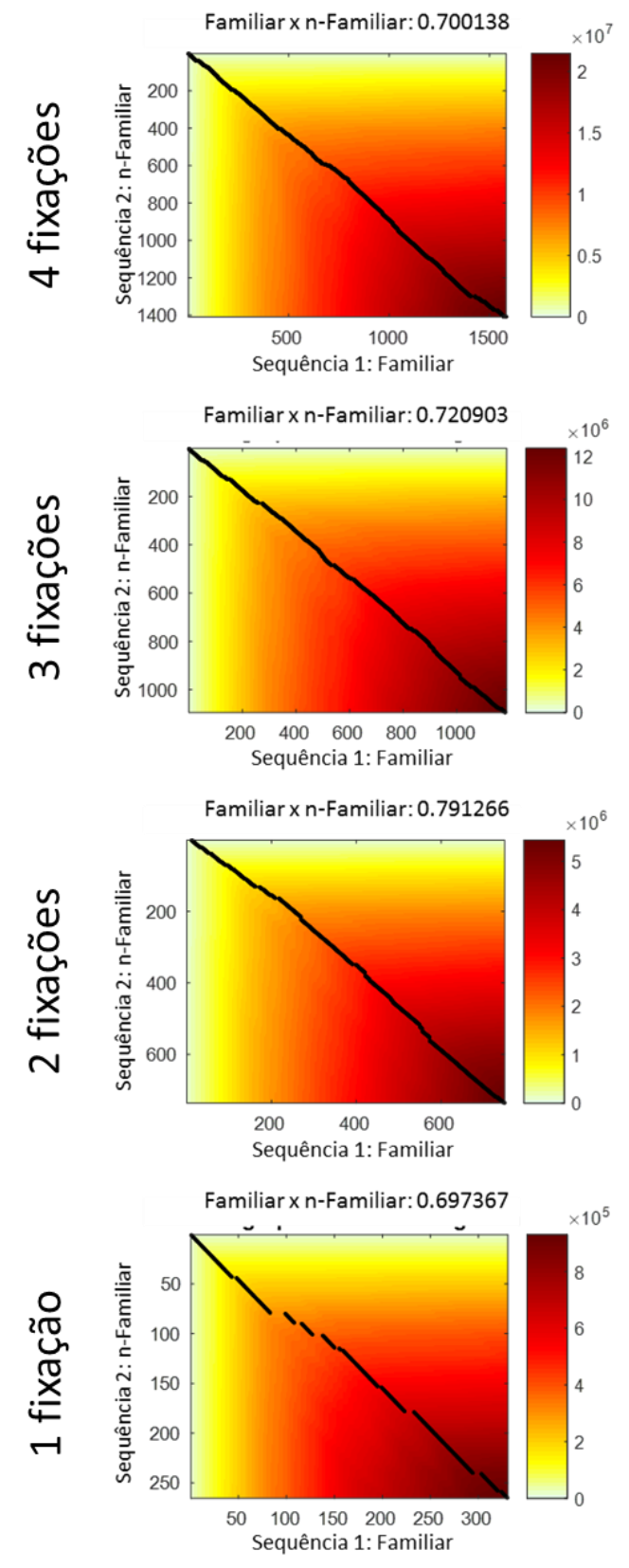
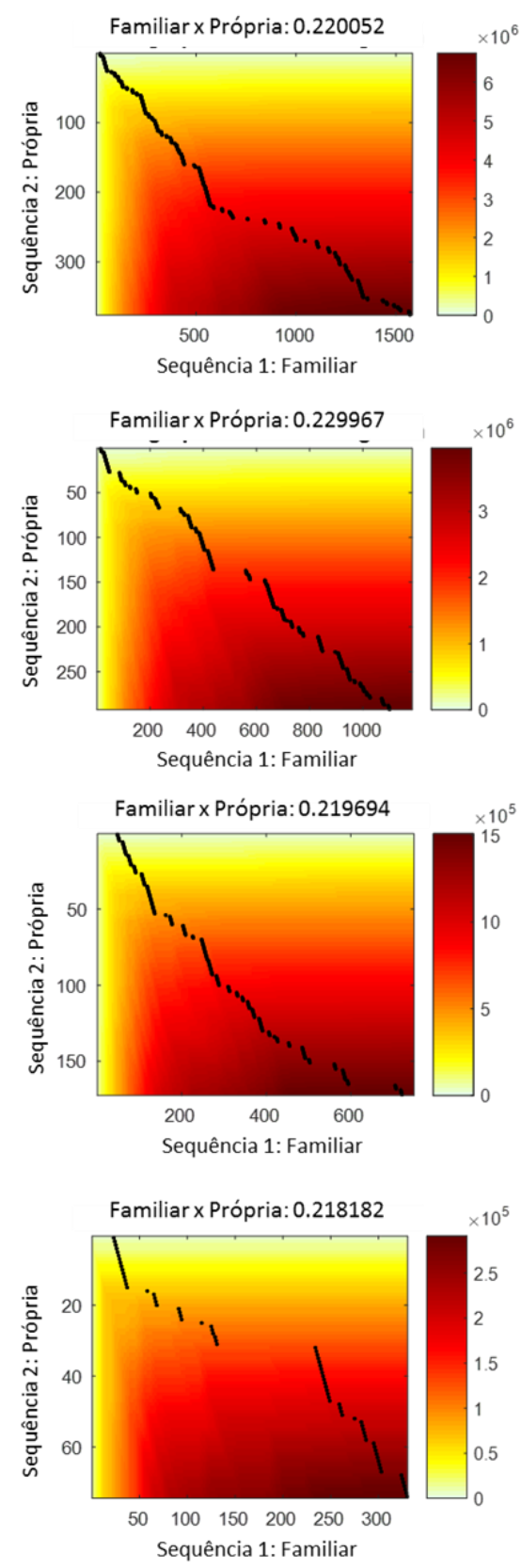
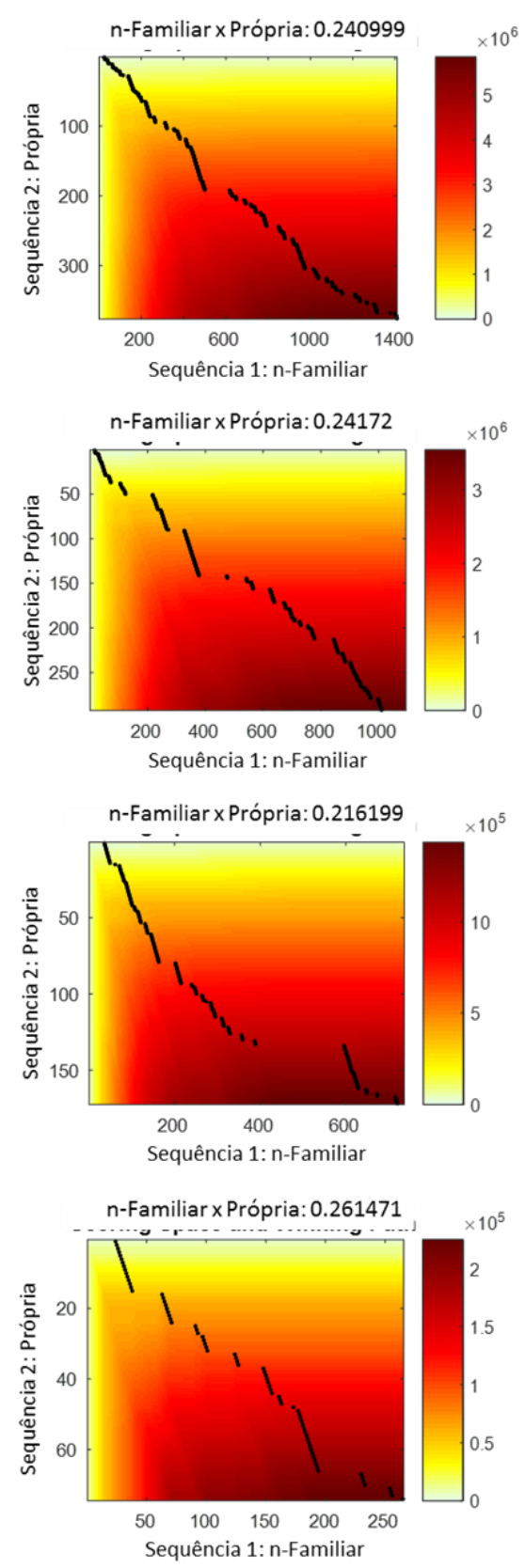